\title{
Pattern-Generating Role for Motoneurons in a Rhythmically Active Neuronal Network
}

\author{
Kevin Staras, György Kemenes, and Paul R. Benjamin \\ Sussex Centre for Neuroscience, School of Biological Sciences, University of Sussex, Falmer, Brighton, \\ United Kingdom BN1 9QG
}

\begin{abstract}
The role of motoneurons in central motor pattern generation was investigated in the feeding system of the pond snail Lymnaea stagnalis, an important invertebrate model of behavioral rhythm generation. The neuronal network responsible for the three-phase feeding motor program (fictive feeding) has been characterized extensively and divided into populations of central pattern generator (CPG) interneurons, modulatory interneurons, and motoneurons. A previous model of the feeding system considered that the motoneurons were passive followers of CPG interneuronal activity. Here we present new, detailed physiological evidence that motoneurons that innervate the musculature of the feeding apparatus have significant electrotonic motoneuron $\rightarrow$ interneuron connections, mainly confined to cells active in the same phase of the feeding cycle (protraction, rasp, or swallow). This suggested that the motoneurons participate in
\end{abstract}

The study of central pattern generators (CPGs) has proved to be a profitable strategy for elucidating cellular mechanisms underlying motor behavior. These neuronal oscillatory networks have been investigated in both vertebrate and invertebrate preparations, and shared principles of organization have emerged. For example, there is increasing evidence from both mammalian (Windhorst, 1990) and nonmammalian vertebrate systems (Perrins and Roberts, 1995a,b) that motoneurons may have a dynamic role in contributing to the patterned output through central feedback pathways to CPG interneurons. In some invertebrate CPGs, which are thought to serve as useful general models for rhythmically active neuronal networks, motoneurons have been demonstrated to make a similarly active contribution to patterned output. Indeed, in the lobster stomatogastric system, the CPGs consist of single populations of neurons that perform shared motoneuronal and interneuronal rhythm-generating roles (Selverston and Moulins, 1985). In most other systems, however, separate sets of CPG interneurons and motoneurons are present more obviously. Although there is evidence that motoneurons can have an influence on the generation of the motor pattern in such systems, too (Heitler, 1978; Friesen, 1989), the cellular mechanisms integrating interneuronal and motoneuronal activity are not understood clearly.

\footnotetext{
Received Oct. 31, 1997; revised Feb. 27, 1998; accepted March 4, 1998.

This work was supported by Biotechnology and Biological Sciences Research Council Grant GR/J33234 (United Kingdom).

Correspondence should be addressed to Dr. Kevin Staras (c/o Dr. G. Kemenes), Sussex Centre for Neuroscience, School of Biological Sciences, University of Sussex, Falmer, Brighton, United Kingdom, BN1 9QG.

Dr. Staras's present address: Department of Physiology, Royal Free Hospital, School of Medicine, Rowland Hill Street, London NW3 2PF, United Kingdom.

Copyright (C) 1998 Society for Neuroscience $\quad 0270-6474 / 98 / 183669-20 \$ 05.00 / 0$
}

rhythm generation. This was assessed by manipulating firing activity in the motoneurons during maintained fictive feeding rhythms. Experiments showed that motoneurons contribute to the maintenance and phase setting of the feeding rhythm and provide an efficient system for phase-locking muscle activity with central neural activity. These data indicate that the distinction between motoneurons and interneurons in a complex CNS network like that involved in snail feeding is no longer justified and that both cell types are important in motor pattern generation. This is a distributed type of organization likely to be a general characteristic of CNS circuitries that produce rhythmic motor behavior.

Key words: motoneuron; pattern generation; feeding system; molluscs; Lymnaea; electrotonic coupling; feedback

An understanding of the nature of the pathways linking motoneurons to interneurons in a variety of model systems is essential in testing general ideas about the dependency of pattern generation on the synaptic integration of activity of both types of cell. This can be achieved only by experiments offering detailed physiological evidence of synaptic interactions between motoneurons and CPG interneurons in well characterized motor circuits. Here we consider this integrative function in a centrally located motor network, the feeding system of the snail Lymnaea, in which many of the neuronal elements involved in rhythm generation have been identified, allowing synaptic connectivity to be determined by direct intracellular recording. This model also is used extensively in studies on neurotransmitter function (Elliott and Kemenes, 1992; Elphick et al., 1995; Yeoman et al., 1996) and neurophysiological correlates of learning (Whelan and McCrohan, 1996; Kemenes et al., 1997; Kojima et al., 1997; Staras et al., 1998) in which a detailed knowledge of all cell types involved in the pattern generation is essential. The three-phase feeding cycle is produced primarily by an interconnected network of interneurons that activate different types of motoneurons firing in the three different phases of feeding (Benjamin and Rose, 1979; Rose and Benjamin, 1979; Benjamin and Elliott, 1989). Previously, the motoneurons have been considered as passive followers of a CPG interneuron circuit, playing no part in pattern generation or modulation (Rose and Benjamin, 1981b). However, new evidence is presented here, showing that motoneurons innervating the muscles of the buccal mass make important contributions to an ongoing feeding rhythm through previously unreported electrotonic connections with CPG interneurons and are essential for patterning to occur. These results provide detailed supporting evidence for the principle emerging from several other systems, 
too, that rhythm generation in most motor circuits requires the integrated action of both interneurons and motoneurons, and the results contradict a simple hierarchical model of motor control.

\section{MATERIALS AND METHODS}

Experimental subjects. Specimens of adult Lymnaea stagnalis, obtained from commercial animal suppliers (Blades Biological, Kent, UK), were kept in large holding tanks containing copper-free water on a 12:12 hr light/dark regime and fed lettuce three times a week. Before an experiment the animals were moved into 21 plastic tanks in the laboratory and fed lettuce ad libitum.

Isolated brain preparation. In most experiments an isolated CNS preparation was used that consisted of the paired buccal ganglia, the main ganglionic ring (composed of pedal, pleural, parietal, visceral, and cerebral ganglia), and a small length of esophagus (Benjamin and Rose, 1979). The preparation, maintained in HEPES-buffered saline (Benjamin and Winlow, 1981), was pinned down in a Sylgard-coated dish so that the dorsal surface of the buccal ganglia was exposed. In some cases one buccal ganglion was twisted $180^{\circ}$ around the buccal commissure to allow access to neurons on the ventral surface. To facilitate intracellular recording, we removed the outer ganglionic sheath covering the cerebral and buccal ganglia with a pair of fine forceps. The inner sheath was softened by a nonspecific solid protease (Sigma type XIV, Sigma Chemical, Poole, UK) placed on the saline surface above the preparation and left to dissolve for $\sim 1 \mathrm{~min}$. This enzyme treatment was terminated by rapid perfusion of fresh saline via a peristaltic pump.

Buccal mass-CNS preparation. In some experiments in which it was necessary to record simultaneously from neurons and muscles, the CNS and buccal mass, connected either via the latero- and ventrobuccal nerves or the postbuccal nerve, were dissected as one piece. The preparation was bathed in HEPES-buffered saline and arranged in a Sylgard-coated dish so that the dorsal surface of the buccal ganglia was exposed. The buccal mass was opened out by a ventral incision along the midline and pinned flat (dorsal side up) to the Sylgard base to minimize movements caused by muscular contractions. This arrangement exposed the posterior and anterior jugalis and the radula tensor muscles on both sides. The outer ganglionic sheath was removed with fine forceps, but no or only very little protease treatment was administered. These procedures are similar to those described by Peters and Altrup (1984).

Electrophysiological recording techniques. Up to four intracellular recordings were made simultaneously. Glass microelectrodes $(2 \mathrm{~mm}$; Clarke Electromedical, Redding, UK) were pulled on a vertical electrode puller to a resistance of 30-80 M $\Omega$ when filled with $4 \mathrm{M}$ potassium acetate. Signals were fed into amplifiers (Neurolog NL102, Digitimer, Welwyn Garden City, UK) and output to a storage oscilloscope (Gould 1604, Gould Instrument Systems, Hainault, UK), a chart recorder (Gould TA240S), and a DAT recorder (Biologic DTR-1801, Biological Science Instruments, Claix, France).

Identification and selection of cell types. The feeding network in Lymnaea has been characterized extensively so that many individual elements such as CPG interneurons, motoneurons, and modulatory neurons have been identified previously (Fig. $1 A$ ) and their synaptic connectivity determined. Rhythmic feeding behavior is produced by three main types of premotor CPG interneurons, known as N1, N2, and N3 (Rose and Benjamin, 1981a). These control the three main active phases of the behavioral feeding cycle-protraction (N1), rasp (N2), and swallow
(N3) - performed by the muscular feeding organ, the buccal mass. Now there are known to be subtypes of each of these $\mathrm{N}$ cells, the $\mathrm{N} 1$ medial (N1M) and N1 lateral (N1L) cells (Yeoman et al., 1995), the N2 dorsal (N2d) and N2 ventral (N2v) cells (Brierley et al., 1997a), and the N3 tonic (N3t) and N3 phasic (N3p) cells (Elliott and Benjamin, 1985a). Most of these cell types occur as bilaterally symmetrical pairs on the dorsal surface of the buccal ganglia except for the N2v cells, which are located on the ventral surface (Fig. $1 A$ ). The N1M cells recorded here are a single pair of cells that lie beneath the B2 motoneurons on each side. They were backfilled by Kemenes and Elliott (1994) with 5(6)carboxyfluorescein from the contralateral cerebrobuccal connective. These may be the only cells of the N1M type. Previous accounts in which larger numbers of these cells were described (Rose and Benjamin, 1981b; Yeoman et al., 1995) probably were confused by the similar firing patterns of B7 motoneurons, one of which is coupled electrotonically to the N1M cells and fires in a similar pattern (see Results). The methods for identifying the CPG cell types are reviewed by Yeoman and colleagues (1995).

The feeding motoneurons (Fig. 1A) can be identified visually (B1, B2, $\mathrm{B} 3, \mathrm{~B} 4, \mathrm{~B} 4 \mathrm{CL})$ or by the synaptic inputs recorded during fictive feeding rhythms (B7, B10) (Benjamin and Rose, 1979; Rose and Benjamin, 1981a). They fire in response to synaptic inputs from CPG interneurons. In the isolated preparation used here, the fictive feeding pattern was driven by a modulatory interneuron called the slow oscillator (SO). This is a single cell that lies between the $\mathrm{B} 1$ and $\mathrm{B} 2$ motoneurons on either the left or right side (Fig. $1 A$ ). It has a complex set of reciprocal synaptic connections with the CPG neurons (Elliott and Benjamin, 1985b) that in turn drive the motoneurons (Fig. $1 B$ ). The ability of the SO to drive a fictive feeding rhythm in all three types of CPG interneuron is demonstrated directly in Figure 1Ci. Here steady depolarizing current, sufficient to excite the SO, produced rhythmic burst activity in $\mathrm{N} 1 \mathrm{M}, \mathrm{N} 2 \mathrm{~d}$, and $\mathrm{N} 3 \mathrm{p}$ cells recorded at the same time. The characteristic waveforms during $\mathrm{N} 1 /$ protraction, N2/rasp, and N3/swallow are clearer in the faster time base of Figure 1Cii. The main mechanism by which the SO drives the $\mathrm{CPG}$ rhythm is via a strongly facilitating $\mathrm{SO} \rightarrow \mathrm{N} 1$ connection (Rose and Benjamin, 1981a; Elliott and Benjamin, 1985b), although the $\mathrm{SO} \rightarrow \mathrm{N} 2 \mathrm{~d} /$ N2v biphasic input (Yeoman et al., 1993; Brierley et al., 1997b) is also important in triggering the $\mathrm{N} 2$ plateaus (Fig. $1 B$ ). The connections between the $\mathrm{N}$ cells (data not shown in Fig. 1B) allow the full $\mathrm{N} 1 \rightarrow \mathrm{N} 2 \rightarrow \mathrm{N} 3$ fictive feeding sequence to occur. The SO receives feedback from the CPG interneurons (Elliott and Benjamin, 1985b) that entrain its activity to the CPG rhythm (Fig. $1 B$ ). Without this inhibitory feedback from the N2 and N3 CPG interneurons, it fires tonically, having no intrinsic ability to burst.

The main objective of the present experiments was to characterize the synaptic relationships between motoneurons and CPG interneurons. The SO was recorded routinely to drive a fictive feeding rhythm, and then one or more CPG interneurons and motoneurons were recorded together to establish synaptic connectivity and to test the ability of the motoneuron to influence the ongoing feeding rhythm. Some motoneurons for which the anatomy had not been investigated previously were singly injected with the yellow fluorescent tracer 5(6)-carboxyfluorescein (5-CF, 5\%) by passing repeated pulses of hyperpolarizing current through the microelectrode (Kemenes et al., 1991). In Lymnaea, no dye coupling is present between electrotonically coupled neurons injected with fluorescent tracers (G. Kemenes, unpublished observations); therefore, no morphologi-

Figure 1. Motor and interneurons of the feeding system of Lymnaea in the "twisted" buccal ganglion preparation. $A$, The position of identified motor and interneurons that were the subjects of the present study. B1, B2, B3, B4,B4CL, B7a, B7b, B10, Motoneurons; N1M, N1 medial central pattern generator (CPG) interneuron; N1L, N1 lateral CPG interneuron; N2d, N2 dorsal CPG interneuron; N2v, N2 ventral CPG interneuron; N3p, N3 phasic CPG interneuron; $N 3 t, \mathrm{~N} 3$ tonic $\mathrm{CPG}$ interneuron; $S O$, slow oscillator modulatory interneuron. Nerves of the buccal ganglia include $C B C$, cerebrobuccal connective; $B C$, buccal commissure; $D B N$, dorsobuccal nerve; $L B N$ and $V B N$, latero-/ventrobuccal nerve; and $P B N$, postbuccal nerve. $A$, Anterior; $P$, posterior; $L$, left; $R$, right. $B$, A summary diagram of the reciprocal synaptic connections between the modulatory SO cell and each of the feeding CPG interneurons, based on previous studies. Depolarization of the SO drives the CPG interneurons through these identified connections. The interneurons, in turn, produce the three-phase fictive feeding rhythm through complex synaptic connections (Elliott and Benjamin, 1985a) among N1, N2, and N3 phase cells (data not shown). Activity in the SO is entrained to the CPG rhythm by feedback from the interneurons. Black bars, Excitatory connections; black circles, inhibitory connections. The motoneurons $(M N S)$ active in the three different phases of feeding $(P$, protraction; $R$, rasp; $S$, swallow) are driven by interneurons active in the same phase. $C$, Depolarizing current injected into the modulatory interneuron SO can drive a fictive feeding rhythm via sequential activation of the CPG interneurons. $\mathrm{C}$, Maintained depolarization sufficient to excite the SO produces rhythmic burst activity in N1M, N2d, and N3p cells recorded at the same time. Cii, Expanded time base showing the characteristic waveforms of synaptic potentials and firing patterns of interneurons during N1/protraction, N2/rasp, and N3/swallow. The synaptic connections between the N cells allow the full N1-N2-N3 fictive feeding sequence to occur. 
A

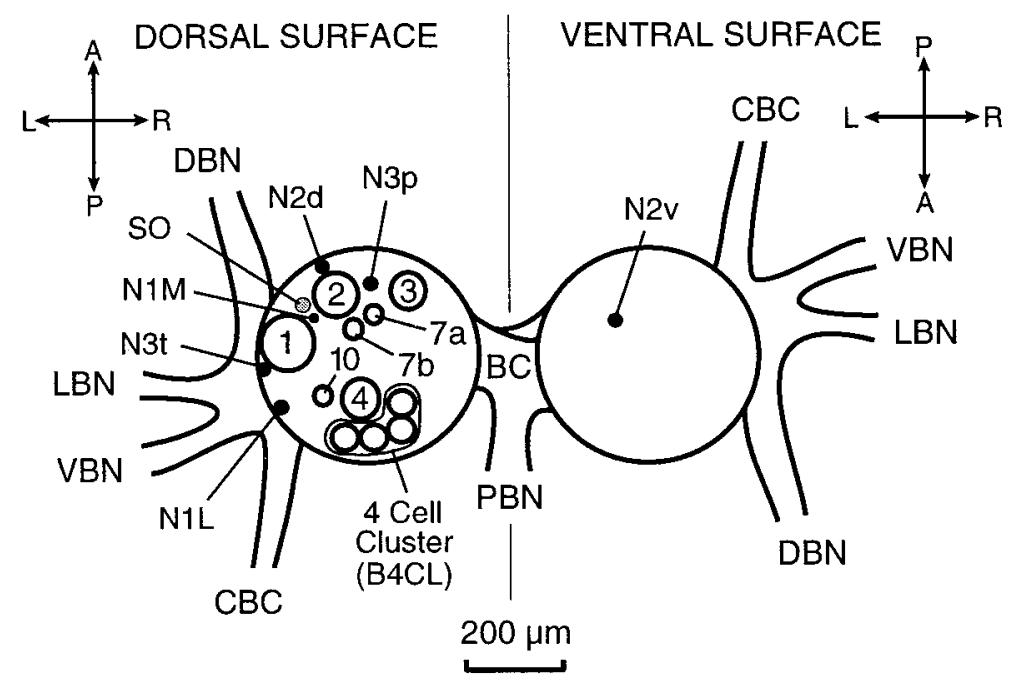

B

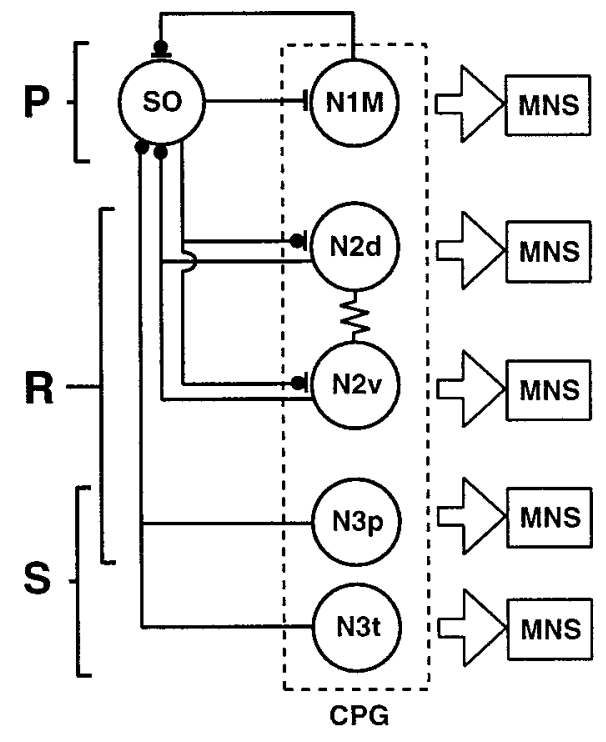

Ci
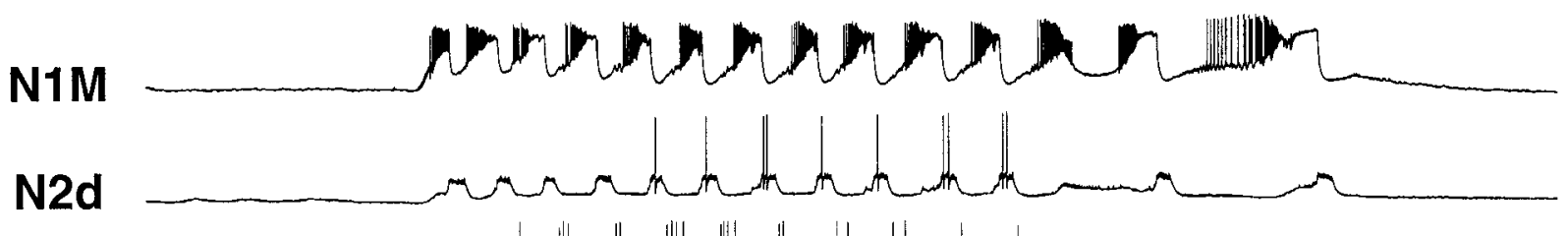

N3p

so

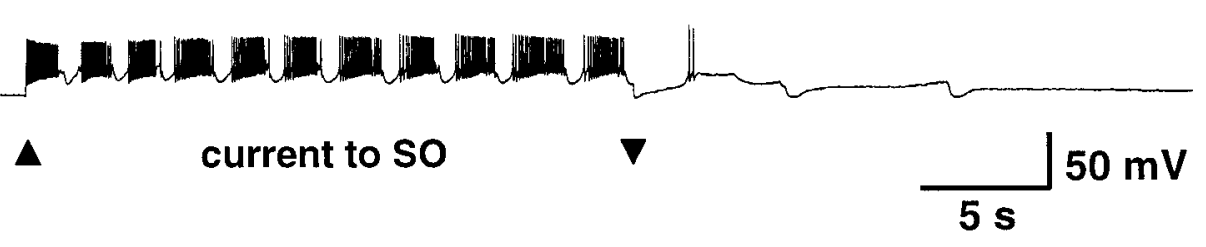

Cii

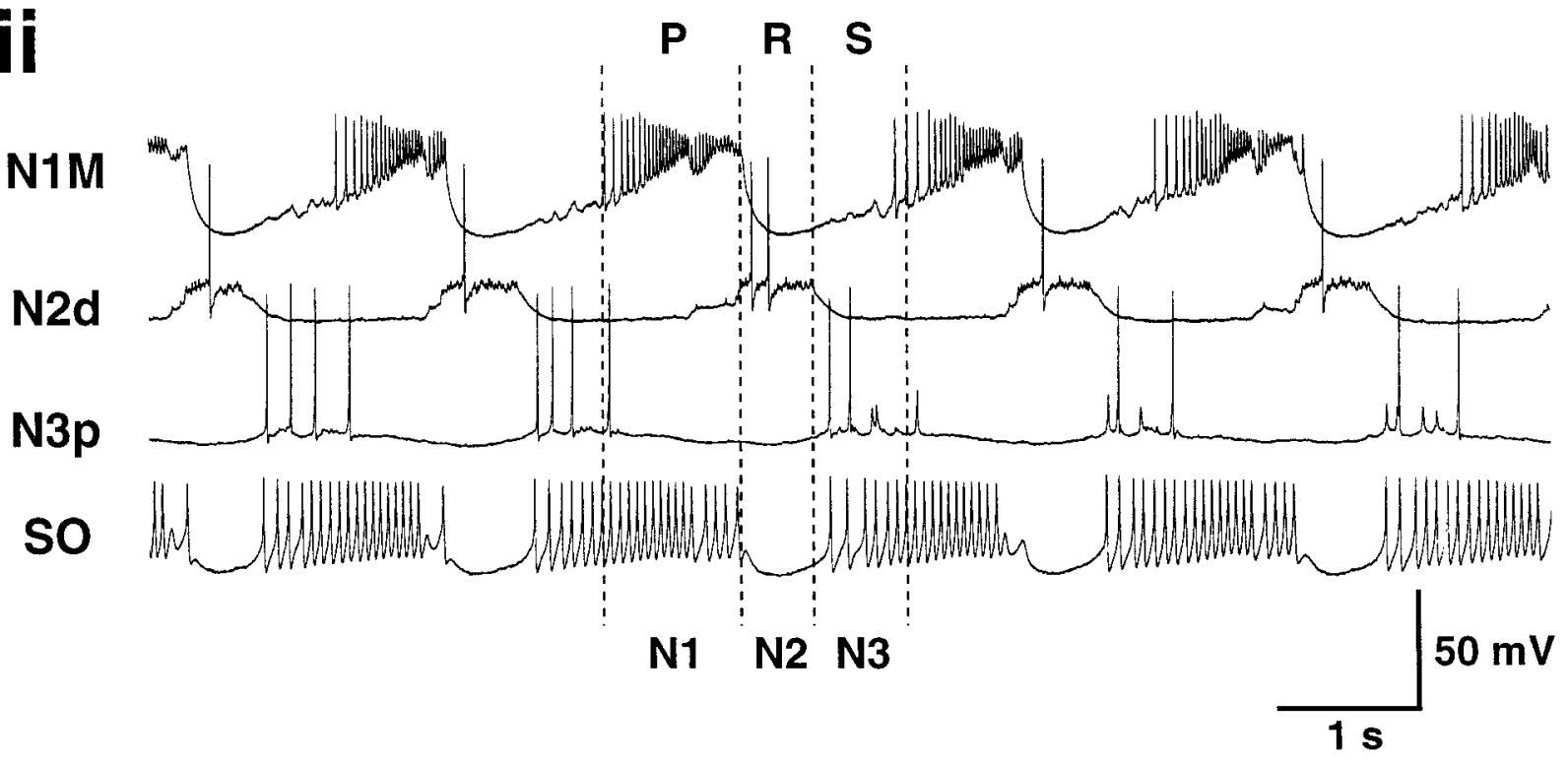


cal confirmation of electrotonic coupling could be made by injecting motoneurons singly. However, we used double fills of motoneurons and interneurons with two different fluorescent dyes to see if there was an overlap of neurites. Although this in itself is not sufficient to prove synaptic connectivity, it provides some morphological evidence for the likely sites of contact between cells, the existence of which was demonstrated more directly by physiological experiments (see Results). In these experiments the motoneuron was always injected with 5-CF, and the interneuron was injected with the blue fluorescent tracer methoxypyrenetrisulfonic acid (MPTS, 20\%; Molecular Probes, Eugene, OR). Photomicrographs were taken from fresh whole mounts under ultraviolet light, using a compound light microscope equipped with a 450-490 nm exciter filter, an FT 510 chromatic beam splitter, and an LP 520 barrier filter. This filter combination allowed both a full assessment of gross cell morphology at lower magnifications $(5 \times$ and $10 \times$ objectives $)$ and visualization of overlapping neurites at higher magnifications from the two neurons injected with the two different dyes (with the $20 \times$ objective the depth of field is $4160 \mathrm{~nm}$ and the resolution is $634 \mathrm{~nm}$; with the $40 \times$ objective with oil immersion the depth of field is $932 \mathrm{~nm}$ and the resolution is $244 \mathrm{~nm}$ ).

Experimental protocol. The main type of synaptic connections that were discovered was electrotonic. When we assessed electrotonic coupling strengths between a motoneuron and an interneuron, the motoneuron into which current was to be injected was always impaled with two electrodes (one to inject current and one to record membrane potential) to allow the accurate recording of membrane potential. When we tested for the presence of an electrotonic junction, the amount and duration of current injection were standardized with the use of a current injection monitor and a square-wave pulse generator. The preparations were dissected and bathed continuously in normal HEPES-buffered saline. In some cases the electrotonic nature of synapses was confirmed by perfusing the preparation for $50 \mathrm{~min}$ in a high $\mathrm{Mg}^{2+}$, low $\mathrm{Ca}^{2+}$ saline plus EGTA (HiLo+EGTA) (composition described in Yeoman et al., 1993). This contains virtually no $\mathrm{Ca}^{2+}$ and nine times the concentration of $\mathrm{Mg}^{2+}$ present in normal saline and blocks chemical synapses by replacing the $\mathrm{Ca}^{2+}$ ions necessary for synaptic transmission with $\mathrm{Mg}^{2+}$. For assessing the contribution of a motoneuron to pattern generation, we used only preparations in which the SO was capable of driving a regular fictive feeding pattern within the physiological feeding range observed in intact feeding animals (15-30 bites/min). Resetting experiments were performed by manipulating motoneuron activity during SO-driven fictive feeding rhythms. Where possible, the motoneuron was impaled with two independent electrodes to provide a balanced DC recording. At least five full regular SO-driven feeding cycles were required before firing activity was manipulated in the target cell. Activation or suppression of the motoneuron was performed by applying either depolarizing or hyperpolarizing current pulses into the soma. The duration of the bursts evoked by the depolarizing current did not exceed the duration of bursts in the CPG-driven cycles (for statistical details, see Results). Current injection into the SO was maintained throughout this period and until at least five further cycles had elapsed. Control experiments were performed in which the SO was used to drive the rhythm, but the activity of motoneurons was not manipulated. In most instances it proved possible to perform motoneuron activation, suppression, and control experiments within a single preparation.

In these resetting experiments our primary objective was to remove or add bursts of motoneuron spikes during an ongoing SO-driven fictive feeding rhythm and, in the case of current-induced firing, still maintain both spike activities and membrane potentials within the normal operating range of the manipulated motoneurons. That this was true was confirmed by comparing a variety of parameters of motoneuronal activity, such as spike frequencies and membrane potential changes in each type of motoneuron seen in artificially evoked and CPG-driven bursts. This analysis was confined to motoneurons that in preliminary experiments were shown to influence the rhythm (B7, B10, and B4; also see Results). For the B7 motoneuron this comparison showed that the instantaneous spike frequency in current-induced bursts $[27.0 \pm 2.2(\mathrm{SE})$ spikes/sec, $n=8$ from three experiments] was within the range seen in the CPG-driven bursts immediately preceding them (from $2.5 \pm 1.0$ to $26.6 \pm 3.0$ spikes/sec). Similarly, data were obtained for the B10 (currentinduced, $30.1 \pm 0.7$ spikes/sec; $\mathrm{CPG}$-driven, from $3.6 \pm 1.3$ to $39.0 \pm 3.9$ spikes/sec, $n=4$ from two experiments) and B4 cells (current-driven, $27.5 \pm 1.8$ spikes/sec; CPG-driven, from $3.8 \pm 0.7$ to $33.5 \pm 3.5$ spikes/ sec, $n=10$ from four experiments). Individual examples of this are given in Results for B7 (see Fig. 5Cii), for B10 (see Fig. 7Aii), and for B4 motoneurons (see Fig. 10Ci). A statistical analysis (paired Student's $t$ tests) revealed no significant differences between the frequency of spikes in current-induced bursts and the highest instantaneous spike frequencies seen in CPG-driven bursts in $\mathrm{B} 7$ ( $\mathrm{df}=7, t=0.05 ; p=0.96), \mathrm{B} 10$ $(\mathrm{df}=3, t=2.28 ; p=0.11)$ or $\mathrm{B} 4(\mathrm{df}=9, t=-1.67 ; p=0.13)$.

As well as showing that the rates of firing of the current-injected motoneurons were within the physiological range, it was also necessary to show that changes in underlying membrane potential evoked by current injection were similarly physiological. This was confirmed by measuring the amplitude range of depolarizing shifts resulting from excitatory synaptic inputs during five cycles of activity preceding the motoneuron stimulation in each SO-driven episode of fictive feeding ( $n=8$ from three experiments for $\mathrm{B} 7, n=4$ from two experiments for $\mathrm{B} 10$, and $n=$ 10 from four experiments for B4) and comparing them with the levels of depolarization used to evoke spike activity in the motoneurons. During SO-driven episodes of fictive feeding the ranges of depolarizing membrane potential changes from resting were from $10.0 \pm 1.1$ to $37.3 \pm 1.0$ $\mathrm{mV}$ for B7 (measured from 40 cycles), from $4.8 \pm 0.3$ to $19.0 \pm 0.6 \mathrm{mV}$ for B10 (measured from 20 cycles), and from $8.5 \pm 0.6$ to $19.0 \pm 0.6 \mathrm{mV}$ for B4 (measured from 50 cycles). In experiments in which the motoneurons were recorded together with $\mathrm{CPG}$ interneurons active in the same phase, all current-induced depolarizing shifts were between 10 and 20 $\mathrm{mV}$ (measured through a second electrode in the motoneurons); in most cases these induced strong spike activity in the interneurons. Individual examples of this are given in Results for B7 (N1M input, Fig. 2B), for $\mathrm{B} 10$ (N2d and N2v input, Fig. $7 E$ ), and for B4 motoneurons (N3t input, Fig. $9 B)$. Interpretation of these records will be presented in more detail in Results. In experiments in which, for technical reasons, it was not possible to measure accurately the membrane potential changes through a second electrode while injecting current into a motoneuron, the spike frequency served as an indicator of whether or not the cell was still in its normal physiological range. This was possible because for all three types of motoneuron both the relationship between the injected current and resulting membrane voltage change and the relationship between membrane voltage change and spike frequency were found to be linear within the range used in these experiments.

In the experiments designed to test the effect of suppression of motoneurons on ongoing CPG activity, we used hyperpolarizing currents evoking voltage changes in the physiological membrane potential range of motoneurons. Initial experiments testing the coupling between motoneurons and interneurons were done with a range of hyperpolarizing current intensities as well as depolarizing pulses. Significant inhibitory effects were seen on the interneurons at current intensities that produced voltage changes in the physiological membrane potential range of the motoneurons. Thus a $\sim 30 \mathrm{mV}$ drop in the B7a membrane potential was found to cause a $\sim 5 \mathrm{mV}$ drop in the N1M membrane potential; a $\sim 20$ $\mathrm{mV}$ drop in B10 membrane potential caused a $\sim 7 \mathrm{mV}$ change in $\mathrm{N} 2 \mathrm{~d}$; a $\sim 4 \mathrm{mV}$ change in $\mathrm{N} 2 \mathrm{v}$ and $\mathrm{a} \sim 25 \mathrm{mV}$ drop in $\mathrm{B} 4$ membrane potential caused a $\sim 8 \mathrm{mV}$ change in $\mathrm{N} 3 \mathrm{t}$ (the values given for the motoneurons are maximum changes caused by inhibitory CPG inputs, measured in the same cells firing in fictive feeding patterns). The same physiological levels of stimulation were used when current was passed through the recording electrode, and this can be confirmed by measuring the resulting voltage changes in the interneurons (see Figs. $6 A, 8 A, 10 C$ ).

\section{RESULTS}

\section{Motoneuron connections with interneurons}

The main aim of this work was to obtain detailed evidence for the synaptic connectivity of motoneurons and interneurons in the Lymnaea feeding system and to show that integrated activity of both types of cells was essential for motor pattern generation.

Initially, intracellular pairwise recordings from a variety of motoneurons and interneurons revealed that, in addition to previously reported interneuron $\rightarrow$ motoneuron chemical synapses (Elliott and Kemenes, 1992; Brierley et al., 1997a), electrotonic connections between the two cell types also existed. The electrotonic synapses had DC coupling coefficients (measured by applying square-wave current pulses into the cell bodies of recorded presynaptic neurons) ranging from $12 \%$ to $36 \%$. These connections were present only between motoneurons and interneurons active in the same phase of the feeding cycle. 


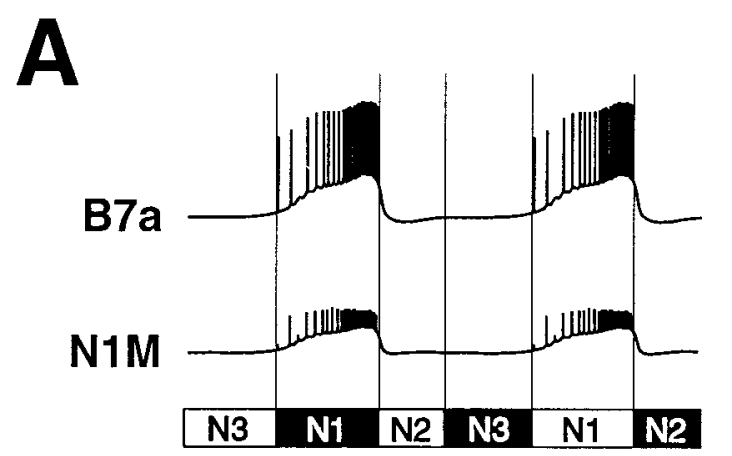

C i NORMAL ii hiLo+EGTA

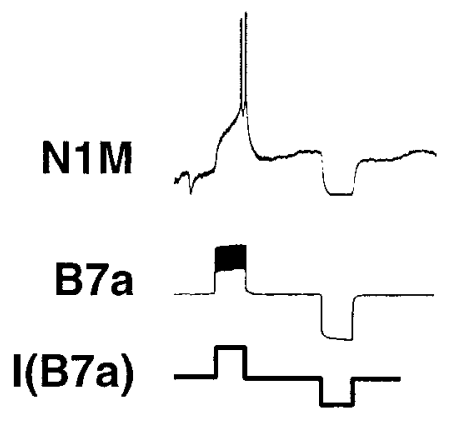

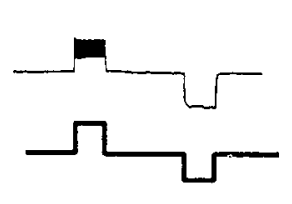

$110 \mathrm{mV}$

$5 \overline{\sec } \mid 50 \mathrm{mV}$

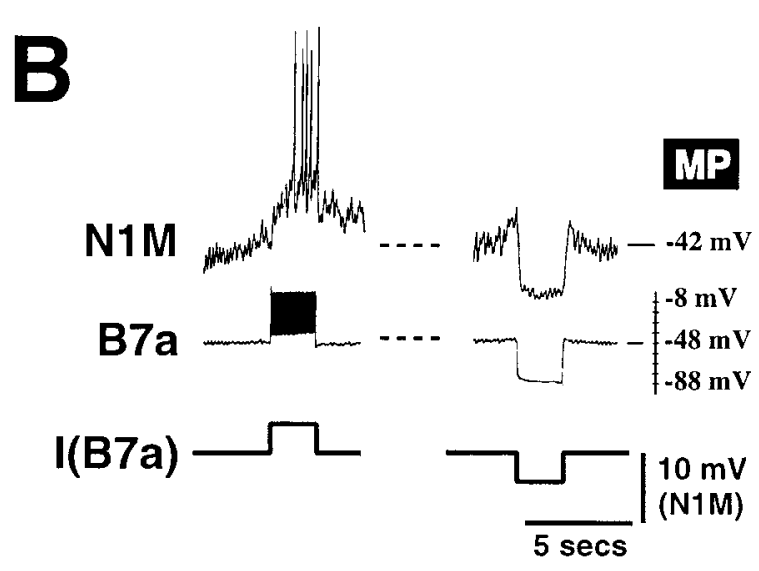

D i nORMAL ii hilo+EGta

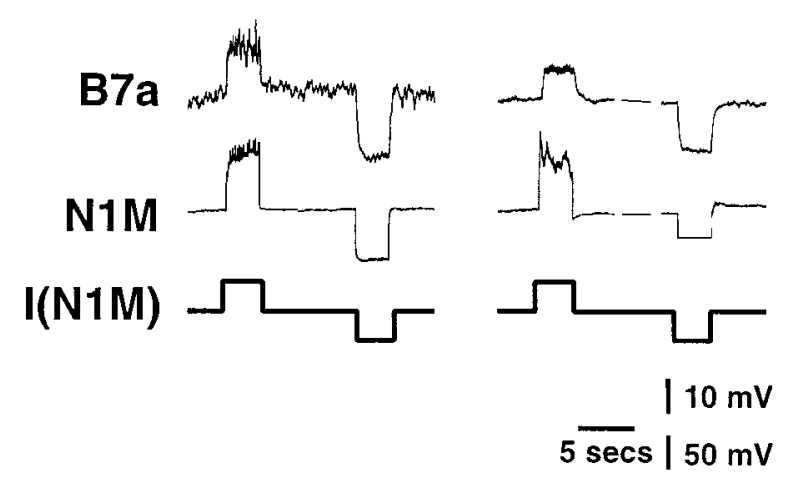

Figure 2. Electrotonic coupling between the protraction phase B7a motoneuron and the N1M CPG interneuron. $A$, Diagram showing the firing pattern of the B7a and N1M neurons in a CPG-driven fictive feeding rhythm. Both neurons fire together in the N1 (protraction) phase and are inhibited during the $\mathrm{N} 2$ and $\mathrm{N} 3$ phases. $B$, Depolarizing or hyperpolarizing current injected into B7a produces similar, although attenuated, voltage changes in N1M. Membrane potential (MP) changes in B7a were measured through a second voltage recording electrode so that coupling coefficients could be determined accurately. $C$, The B7a $\rightarrow \mathrm{N} 1 \mathrm{M}$ connection $(C i)$ is retained in HiLo+EGTA saline (Cii), which blocks chemical synapses and confirms the electrotonic nature of the connection. $D$, The $\mathrm{N} 1 \mathrm{M} \rightarrow \mathrm{B} 7$ a connection also involves an electrotonic synapse $(D i)$, which persists in HiLo+EGTA saline (Dii). Note that in $C$ and $D$ all recordings were made through single current-passing electrodes, and so the presence of coupling could be established but could not be assessed quantitatively.

\section{B7 motoneuron coupling with the protraction phase interneuron, N1M}

The motoneuron B7 and the CPG interneuron N1M fire together in the protraction (N1) phase of feeding (Fig. 2A). The B7 showed strong electrotonic coupling $(n=5$; maximum DC coupling coefficient, 17\%) with N1M (Fig. 2B). Although three to four B7-type motoneurons are present within each buccal ganglia (Benjamin and Rose, 1979), only one or two of these cell types, located between the B2 and B3 motoneurons, were found to show electrotonic coupling with the N1M interneurons. For clarity, the coupled B7 type was renamed B7a, and the noncoupled type was renamed $\mathrm{B} 7 \mathrm{~b}$.

Hyperpolarizing or depolarizing B7a produced equivalent, although attenuated, voltage changes in the N1M cell (Fig. 2B). This was sufficient to drive spike activity in the N1M if a strong burst of spikes was elicited in B7a (Fig. $2 B$ ). Both the firing rate of the current-evoked burst of spikes (29 spikes/sec) and the size of the underlying depolarization $(10.0 \mathrm{mV})$ in Figure $2 B$ were within the physiological range (from $2.5 \pm 1.0$ to $26.6 \pm 3.0$ spikes/sec and from $10.0 \pm 1.1$ to $37.3 \pm 1.0 \mathrm{mV}$, respectively).
The connection persisted in a HiLo+EGTA saline, which blocks chemical synapses, and confirmed the electrotonic nature of the connection (Fig. 2C, $n=3$ ). The synaptic connection in the reverse direction, from $\mathrm{N} 1 \mathrm{M} \rightarrow \mathrm{B} 7 \mathrm{a}$, was investigated also (Fig. $2 D, n=3$ ). Previous work using pharmacological blocking agents has shown that the N1M has cholinergic chemical synapses with many of the feeding motoneurons (Elliott and Kemenes, 1992). However, it was also apparent from this study that a component of the $\mathrm{N} 1 \mathrm{M} \rightarrow \mathrm{B} 7 \mathrm{a}$ synaptic connectivity is electrotonic because it persisted in a HiLo+EGTA saline (Fig. 2Dii). The absolute magnitude of the connection was reduced in HiLo+EGTA saline, confirming that a chemical synaptic component normally is present (for more evidence, see Elliott and Kemenes, 1992). However, in this investigation, which was concerned mainly with the role of the motoneurons, the relative contribution of electrotonic and chemical components of this synapse response was not examined quantitatively.

Dye filling B7a ( $n=7,3$ left and 4 right) with 5(6)carboxyfluorescein (5-CF) revealed a consistent morphology, with extensive neuritic processes in the ipsilateral buccal ganglia 

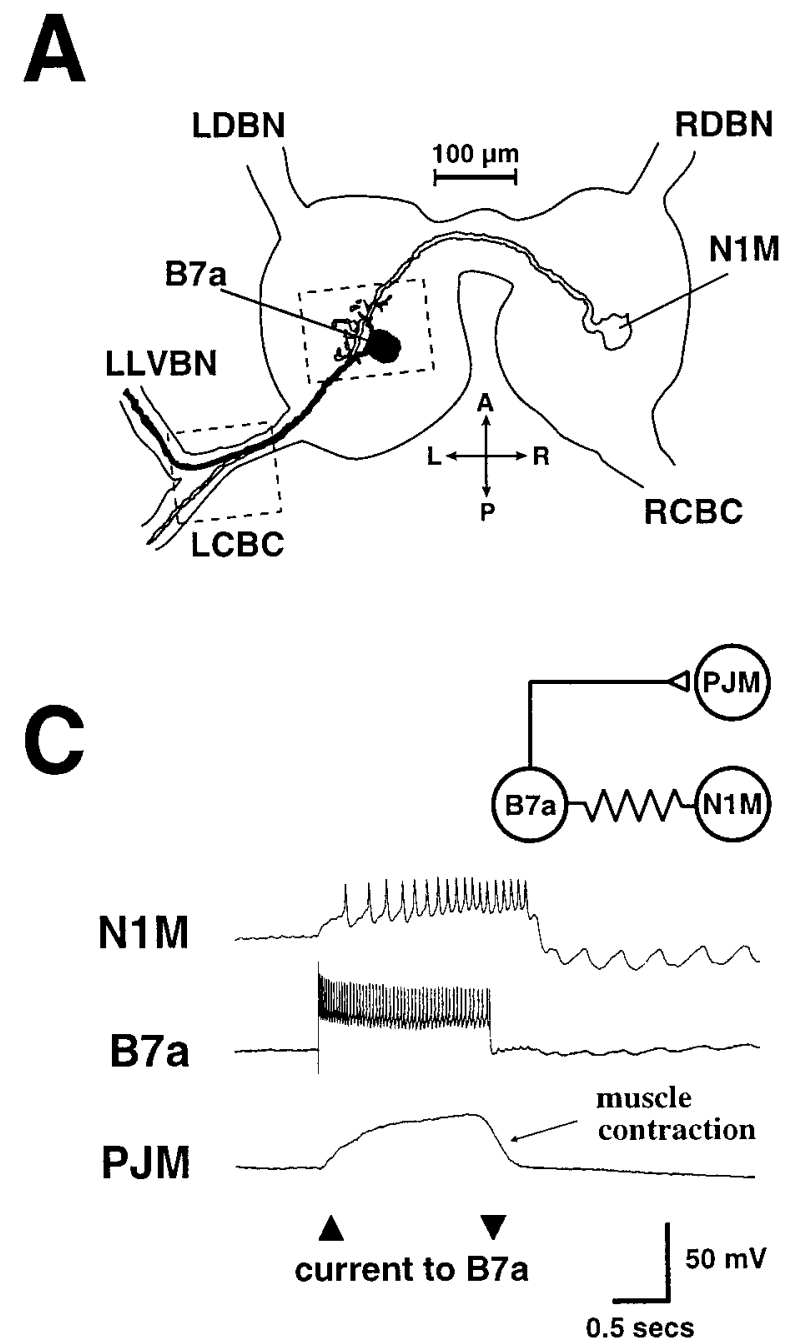

B

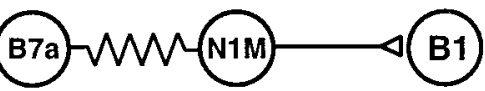

B1

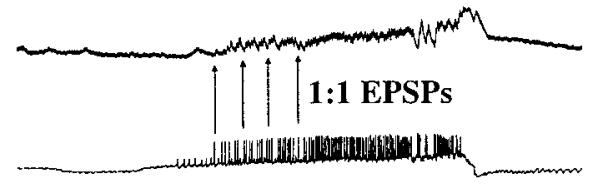

B7a

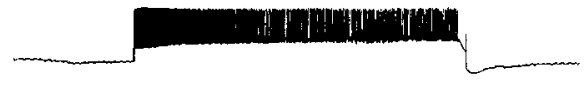

$\Delta$ current to B7a $50 \mathrm{mV}$

$1 \mathrm{sec}$
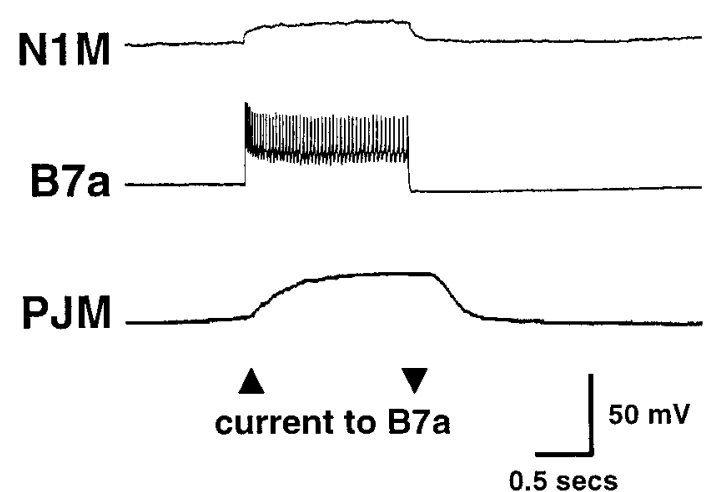

Figure 3. Dual role of the $\mathrm{B} 7 \mathrm{a}$ as a motoneuron and the provider of an excitatory input to a CPG interneuron. $A$, Diagrammatic reconstruction of the morphology seen from joint fills of the B7a (5-CF, yellow; see Fig. 4Ai) and the N1M neurons (MPTS, blue; see Fig. 4Ai). The B7a has a single axon projecting along the $\mathrm{CBC}$ and projecting from the latero- or ventrobuccal nerve roots. The $\mathrm{N} 1 \mathrm{M}$ projects to the contralateral buccal ganglion and through to the contralateral CBC. The neuritic processes of these cells show extensive intermingling, and some of these are potential sites for electrotonic junctions (for high-magnification details of the areas in the rectangles, see Fig. 4Aii, Aiii). B, B7a does not have direct connections with the B1 motoneuron but has indirect effects via the B7a $\rightarrow \mathrm{N} 1 \mathrm{M} \rightarrow \mathrm{B} 1$ pathway. Spikes evoked by depolarizing current injected into B7a excite N1M to firing through the electrotonic coupling between the two cells. Activation of N1M then evokes unitary EPSPs in the B1 through the N1M $\rightarrow$ B1 monosynaptic connection. In the absence of N1M spikes at the beginning of the trace, no inputs are seen on the B1. $C$, Dual function of B7a demonstrated by joint recordings from $\mathrm{N} 1 \mathrm{M}$ and the posterior jugalis muscle $(P J M)$. Activation of B7a evokes activity in the N1M interneuron via the electrotonic coupling. The B7a activation also causes a strong contraction of the protraction phase PJM buccal mass muscle recorded as voltage changes at the tip of a blunted electrode placed on the muscle surface. $D$, Activation of B7a can cause muscle contraction in the absence of spikes in $\mathrm{N} 1 \mathrm{M}$, indicating that the B7a $\rightarrow \mathrm{PJN}$ connection is not mediated by other motoneurons driven by N1M.

Figure 4. Morphological demonstration of potential sites of electrophysiologically confirmed synaptic connections between motoneurons (injected with 5-CF, yellow) and interneurons (injected with MPTS, blue) in the Lymnaea feeding system. Ai, Photomicrograph (magnified $200 \times$, enlarged from a color slide taken through a $10 \times$ microscope objective) of a B7a motoneuron and an N1M interneuron. The main axon branches of the two cells run in close proximity in the buccal neuropile and cerebrobuccal connective. The two axons diverge at the branching point of the cerebrobuccal connective and latero-/ventrobuccal nerve. Aii, High-magnification (600×) photomicrograph (enlarged from a color slide taken through a $40 \times$ microscope objective with oil immersion) showing the area in the rectangle in the left cerebrobuccal connective (LCBC) in Figure $3 A$. The depth of field with this objective and the filter set that has been used is $\sim 0.9 \mu \mathrm{m}$. The thickness of the branches shown is $\sim 4.0 \mu \mathrm{m}$; because the yellow (B7a) and blue (N1M) axons are both in the same $(\sim 0.9 \mu \mathrm{m}$ thick) plane of focus and appear to be in close contact (arrow), this provides a likely anatomical basis for the described electrotonic coupling between them to be direct. Aiii, High-magnification $(600 \times)$ photomicrograph (enlarged from a color slide taken through a $40 \times$ microscope objective with oil immersion) showing the area in the rectangle in the left buccal ganglion in Figure $3 A$. Here, a branch of the initial axon segment of B7a makes a contact with the axon of $\mathrm{N} 1 \mathrm{M}$, making this another potential site of synaptic connections (arrow). B, High-magnification (400 $\times$ ) photomicrograph (enlarged from a color slide taken through a $20 \times$ microscope objective) showing the area in the rectangle (Figure legend continues.) 

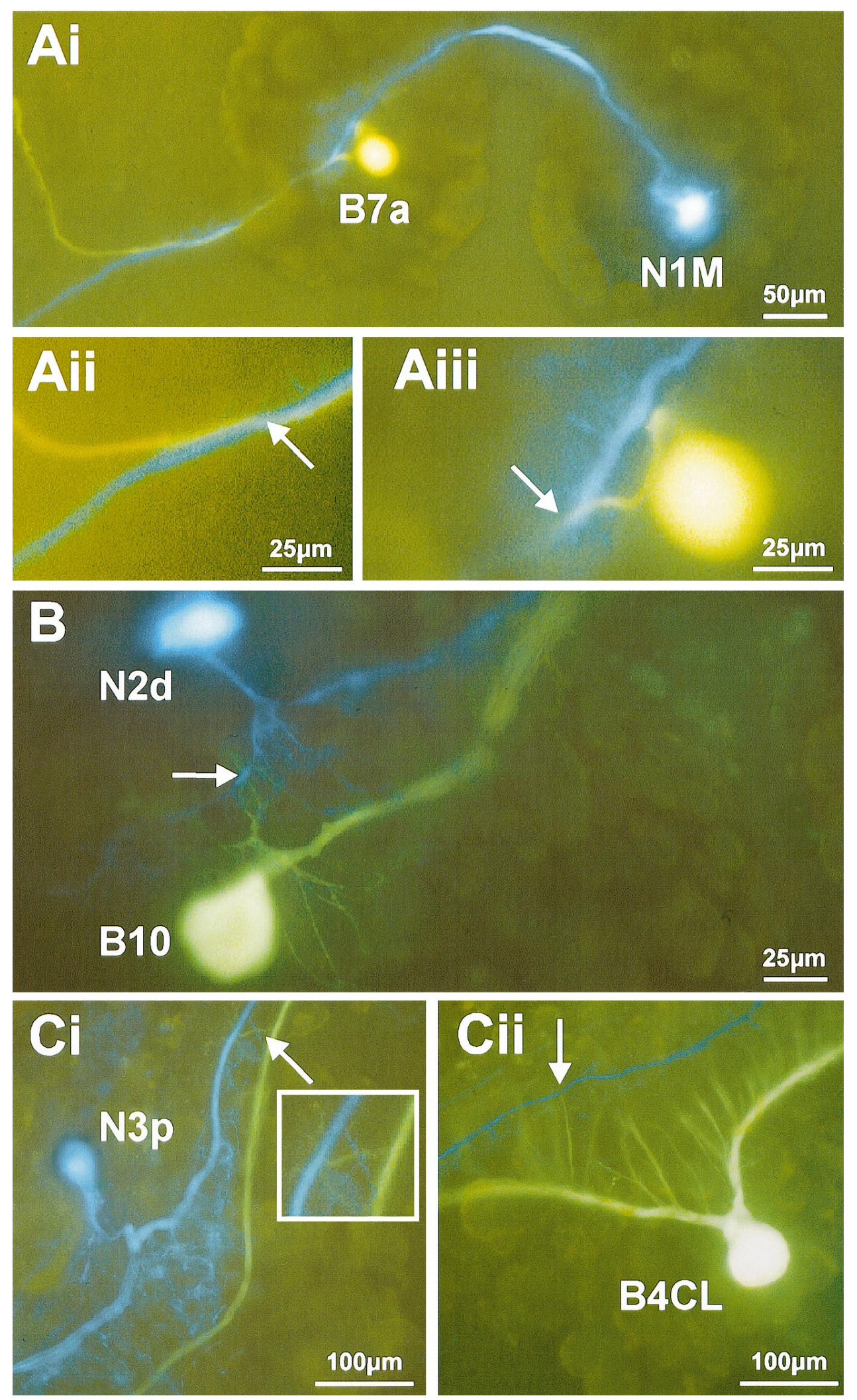

in Figure $7 D$. Neurites from the motoneuron and interneuron are intermingled (arrow) in the region close to the cell bodies. Depth of field with $20 \times$ objective is $\sim 4.0 \mu \mathrm{m}$; the thickness of neurites shown is $\sim 2.5-4.0 \mu \mathrm{m}$. $\mathrm{Ci}$, Photomicrograph (170×, enlarged from a color slide taken through a $20 \times$ microscope objective) showing the area in the rectangle in the left buccal ganglion in Figure $9 E$. Fine branches $(\sim 2.0-4.0 \mu \mathrm{m})$ projecting from the axon of N3p are both in the same plane of focus and appear to be coming into close contact with the axon of a contralateral B4CL (arrowed area shown in inset, magnified $340 \times)$. Cii, Photomicrograph $(170 \times$, enlarged from a color slide taken through a $20 \times$ microscope objective) showing the area in the rectangle in the right buccal ganglion in Figure $9 E$. Fine branches $(\sim 3.0-4.0 \mu \mathrm{m})$ projecting from the initial axon segment of B4CL are both in the same plane of focus and appear to be coming into close contact (arrow) with the axon of the contralateral N3p (same pair of cells as in Ci). 
and a single projection to the ipsilateral latero- or ventrobuccal nerve. Double dye fills $(n=4)$ of both N1M (MPTS, blue) and B7a (5-CF, yellow) showed both the close proximity of their parallel-running axonal projections (Figs. $3 A, 4 A i$ ) and the intermingling of neurites from these two cell types at which the electrotonic junctions (and chemical synapses) presumably are located (Fig. 4Aii,Aiii).

Indirect effects of $\mathrm{B} 7 \mathrm{a}$ activation on other protraction phase motoneurons were seen because of its ability to excite the N1M. An example of this is shown in Figure $3 B$, in which the B1 salivary gland motoneuron received a sequence of EPSPs via the $\mathrm{N} 1 \mathrm{M} \rightarrow \mathrm{B} 1$ excitatory monosynaptic connection (Elliott and Kemenes, 1992). Strongly activating the B7a by depolarizing current evoked spike activity in the N1M that in turn produced 1:1 EPSPs on the B1 cell. It was also possible that the B7a could have more direct synaptic connections with other feeding motoneurons. However, despite extensive investigation the B7a was not found to have direct connections with any of the feeding motoneurons (e.g., B1, B4 etc.). For instance, in Figure 3B, the strong activation of the $\mathrm{B} 7 \mathrm{a}$ neurons at the beginning of the trace produces no obvious synaptic response on the B1 cell until the N1M starts to fire.

Although it was suggested previously that the B7a was a protraction phase motoneuron (Benjamin and Rose, 1979), there was no experimental evidence to support this. However, the peripheral axonal projection described above did indicate that the B7a innervated the buccal mass, the muscular organ responsible for feeding. Using a preparation in which the CNS was left attached to the buccal mass, we found that it was possible to make simultaneous recordings from the buccal ganglion and buccal mass muscles to provide more direct evidence for motoneuronal function. Experiments $(n=2)$ showed that a steady depolarization in $\mathrm{B} 7 \mathrm{a}$ resulted in contraction of the buccal mass posterior jugalis muscle, which is known to be involved in the protraction phase of feeding (Fig. 3C). This strongly indicates a motoneuronal function for the B7a, but because it also excites the N1M cell, it could be that other posterior jugalis muscle motoneurons such as B6 (Rose and Benjamin, 1979) are being activated indirectly by a possible $\mathrm{N} 1 \mathrm{M} \rightarrow \mathrm{B} 6$ excitatory synaptic effect. However, in the experiment shown in Figure $3 D$, even in the absence of N1M activation the posterior jugalis muscle still contracted. The B6 cell, the only other motoneuron type that both fires strongly throughout the protraction phase and projects to the buccal mass (Rose and Benjamin, 1979), is not known to receive an excitatory input from $\mathrm{B} 7 \mathrm{a}$; therefore, the effects of $\mathrm{B} 7 \mathrm{a}$ on the muscle either must be direct or must be mediated by a so-far unidentified motoneuron type as well as by the demonstrated peripheral projections of B7a itself. Although the existence of such a motoneuron type cannot be ruled out entirely, it seems unlikely, because extensive mapping of the feeding network has never revealed any neurons that both projected to the buccal mass and were excited by B7a. In the experiments shown in Figure 3, the current-evoked firing rate of B7a was between 23 and 26 spikes/ sec, within its physiological firing range. These experiments therefore provide evidence that the B7a is a dual function neuron both performing an efferent, probably direct motoneuronal role and providing an excitatory input to the $\mathrm{N} 1 \mathrm{M}$ protraction phase CPG interneuron.

\section{B7a role in pattern generation}

It has been shown previously that the activation of a single N1M interneuron (by injecting depolarizing current) can elicit a full but slow fictive feeding pattern because of its connections with the rest of the CPG network (Elliott and Benjamin, 1985a). Because the B7a was shown to have relatively strong electrotonic connections with the $\mathrm{N} 1 \mathrm{M}$, it raised the possibility that the B7a might have a role in pattern generation. One type of evidence would be if activation of the B7a could drive a feeding rhythm via its coupling with the N1M. In only one preparation of the four tested did steady maintained depolarization of the B7a drive a fast feeding rhythm (Fig. $5 A$ ) in the frequency range normally evoked by activation of modulatory interneurons such as the SO or CV1 $(\sim 0.2 \mathrm{~Hz})$. In this case the N1M was strongly excited and presumably was responsible for activating the CPG via previously established synaptic connections. In three other more typical preparations, depolarization of the B7a eventually could activate $\mathrm{N} 1 \mathrm{M}$ to threshold, but no regular feeding pattern could be elicited (Fig. 5B). The modulatory interneuron SO, recorded simultaneously in both experiments, did not contribute to this activation, so the effects of B7a stimulation were not via this modulatory neuron. These experiments provide some evidence for a role in rhythm generation, but it is unlikely that the B7a cells simply drive the pattern. However, there does appear to be a necessity for B7a activity to achieve rhythm generation, because suppressing the activity of B7a neurons by steady hyperpolarizing current prevents the SO from driving a fictive feeding rhythm. This works best if activity in the B7a has been suppressed before the SO is activated (Fig. 5Ci,Cii). It is less successful if the SO is already driving a rhythm before the B7a is suppressed (data not shown).

A more subtle contributing role to rhythm generation was indicated by experiments like those shown in Figure 6, in which the frequency (Fig. 6A,B) or phase (Fig. 6C) of an SO-driven rhythm could be affected by manipulation of B7a membrane potential and firing activity within its normal physiological range. Hyperpolarizing the B7a slowed the rhythm (Fig. 6 $\mathrm{A}$ ), whereas depolarizing it to fire at higher frequencies $(18.1 \pm 0.9$ spikes $/ \mathrm{sec})$ within its physiological range, as seen in fictive feeding bursts, increased the frequency of the rhythm (Fig. $6 B$ ). The B7a cells fire just before and during N1M activity and via the $\mathrm{B} 7 \mathrm{a} \rightarrow \mathrm{N} 1 \mathrm{M}$ electrotonic connection presumably would contribute to the depolarizing waveform that gradually triggers burst activity in the N1M (arrow in Fig. 6A). It would be predicted that long-term removal of the B7a spike activity would slow the buildup of depolarization, leading to the triggering of the N1 plateau, and slow the frequency of the rhythm, whereas current-induced extra B7a activity would speed it up, leading to an increase in the frequency of the whole rhythm. These two types of effect are shown in the records of Figure 6, $A$ and $B$, respectively. Briefer depolarizing or hyperpolarizing current pulses sufficient to prevent or suppress spike activity in a B7a cell were used to examine if there was a delay or advance in the onset of the next cycle, which may underlie the changes in speed during longer stimulation. An example of this is shown in Figure $6 C$, in which B7a and B 7b cells were recorded and driven into a fictive feeding rhythm by injecting depolarizing current into the SO. The N1M cell was not recorded here, but its effects can be inferred from its known synaptic connections and the records shown in Figure 6, $A$ and $B$. Here, hyperpolarization of the $\mathrm{B} 7 \mathrm{a}$ to prevent one whole burst (Fig. 6Ci) delayed the rhythm, whereas activating the B7a before it normally would fire advanced the next cycle (Fig. 6Cii). In both experiments the expected and actual N2 phases are marked before and after B7a manipulation. The spike frequency of the artificially evoked burst (29.4 spikes/sec) shown in Figure 6Cii again is within the physiological range, and the burst duration (1.3 


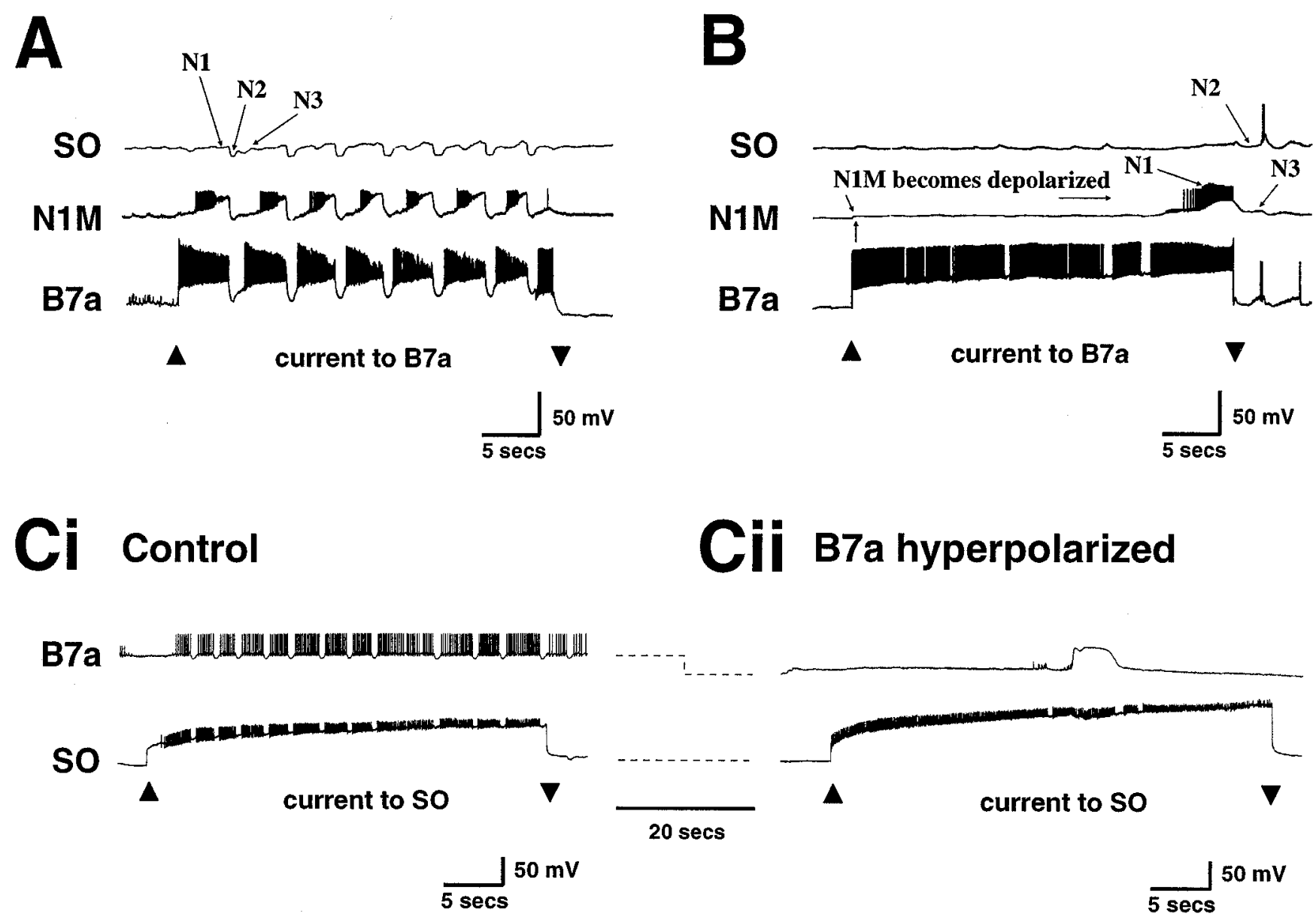

Figure 5. Rhythm-generating function of the B7a motoneuron. $A$, In this preparation the maintained depolarization of B7a could drive a fast fictive feeding rhythm. This occurs via strong activation of the N1M CPG interneuron. The modulatory interneuron, SO, is not activated by B7a but still receives subthreshold synaptic inputs from other CPG interneurons. $B$, In a more typical preparation, maintained depolarization can evoke one or two slow fictive feeding cycles. The B7a $\rightarrow$ N1M electrotonic synapse causes gradual depolarization of N1M, which eventually evokes a full fictive feeding cycle. $C$, Suppression of an SO-driven fictive feeding rhythm by hyperpolarization of B7a. $C i$, In the control condition, maintained depolarization of the SO elicits a fast fictive feeding rhythm, which entrains the B7a. Cii, Maintained hyperpolarization of B7a prevents the same level of depolarizing current injected into the SO from driving a CPG rhythm. This presumably occurs because the hyperpolarized B7a suppresses N1M activity through its electrotonic connections and therefore prevents the SO from driving the CPG.

sec) is not significantly different from the mean duration of the five CPG-driven bursts immediately preceding it $(1.2 \pm 0.2 \mathrm{sec})$. This ability of the $\mathrm{B} 7 \mathrm{a}$ to reset a CPG rhythm is important because data of this type show that the B7a is a member of the CPG network, providing further evidence of a CPG as well as a motoneuronal role.

\section{B10 motoneuron coupling with the rasp phase interneurons, N2d and N2v}

Motoneuron-interneuron electrotonic coupling between cells active in the same protraction phase of the feeding rhythm is important in rhythm generation in the N1M cells and the rest of the CPG network. Does similar same-phase coupling occur with rasp phase cells? Extensive experiments were performed to test whether there were feeding motoneurons that were connected synaptically to the two types of rasp phase CPG interneurons, $\mathrm{N} 2 \mathrm{v}$ and $\mathrm{N} 2 \mathrm{~d}$. The only cell type found to be coupled to these interneurons was the B10 motoneuron. This cell is weakly depolarized during the N1/protraction phase of the feeding cycle but fires mainly during the N2/rasp phase when it is depolarized more strongly (Rose and Benjamin, 1981b). It therefore fires in the same phase as the $\mathrm{N} 2 \mathrm{~d} / \mathrm{N} 2 \mathrm{v}$ cells $($ Fig. $7 A$ ). Like the $\mathrm{B} 7 \mathrm{a} \rightarrow \mathrm{N} 1 \mathrm{M}$ synaptic connection, the nature of the $\mathrm{B} 10 \rightarrow \mathrm{N} 2 \mathrm{~d} / \mathrm{N} 2 \mathrm{v}$ connection was again electrotonic. Both CPG cell types were hyperpolarized or depolarized rapidly by passing square-wave current pulses into B10 (Fig. 7B). Both the firing rate of the current-evoked burst of spikes (28.5 spikes/sec) and the size of the underlying depolarization $(18.7 \mathrm{mV})$ in Figure $7 B$ were within the physiological range (from $3.6 \pm 1.3$ to $39.0 \pm 3.9$ spikes/sec and from $4.8 \pm 0.3$ to $19.0 \pm 0.6 \mathrm{mV}$, respectively). Coupling coefficients were high (maximum DC coupling coefficient between $\mathrm{B} 10 \rightarrow \mathrm{N} 2 \mathrm{~d}$ is $36 \%$, $n=3$; between $\mathrm{B} 10 \rightarrow \mathrm{N} 2 \mathrm{v}$ it is $12 \%, n=3$ ), and coupling persisted in HiLo+EGTA saline, confirming the presence of an electrotonic synapse (Fig. $7 C, n=3$ ). The exact contribution of the direct coupling between B10 and the two types of N2 cells was difficult to ascertain, because the N2d and N2v cells themselves are coupled electrotonically (Brierley et al., 1997a). It is possible that some of the electrotonic effects of B10 on one or another of the N2 cells were indirect, because the recorded electrotonic coupling between $\mathrm{N} 2 \mathrm{~d}$ and $\mathrm{N} 2 \mathrm{v}$ was $\sim 30 \%$.

Intracellular dye fills of the B10 ( $n=6,3$ left and 3 right) 


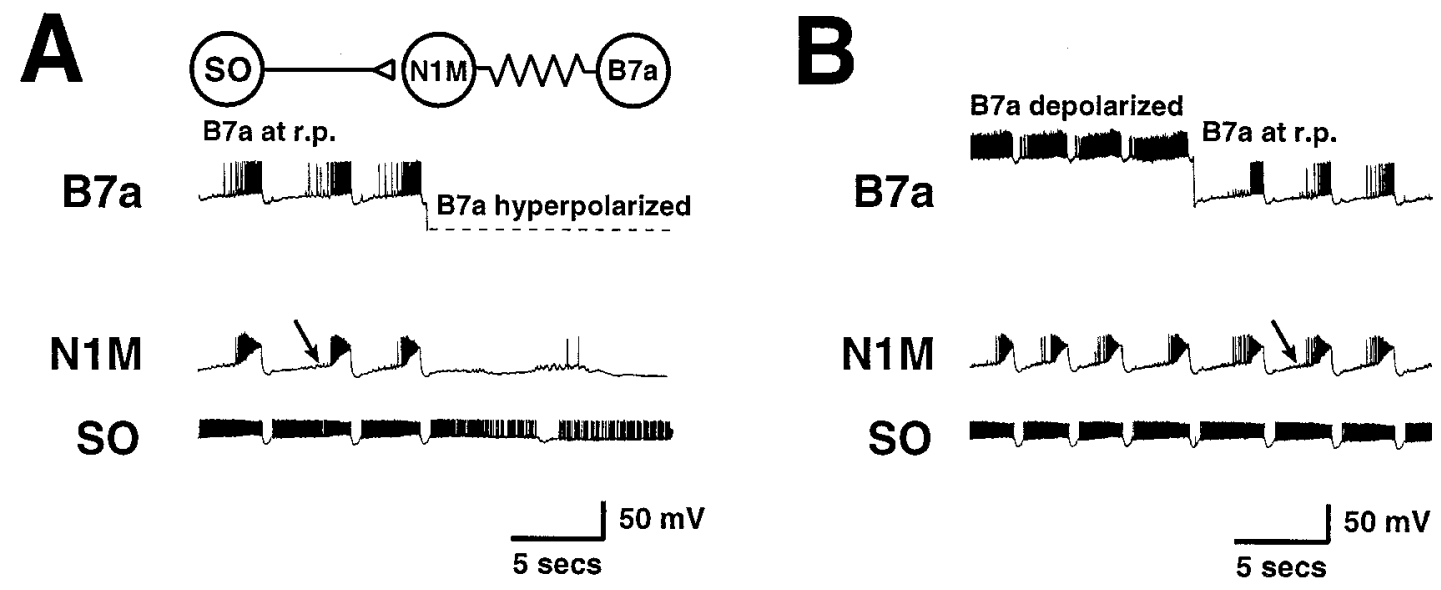

\section{Ci Hyperpolarization}

B7a

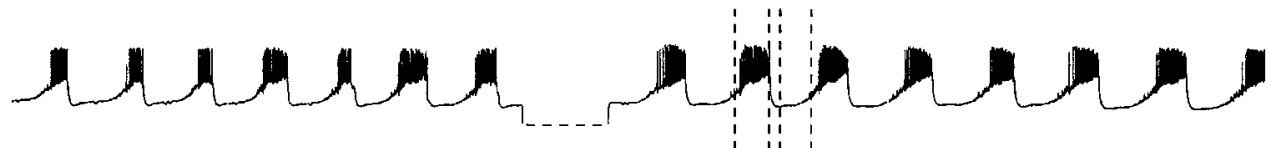

B7b

so

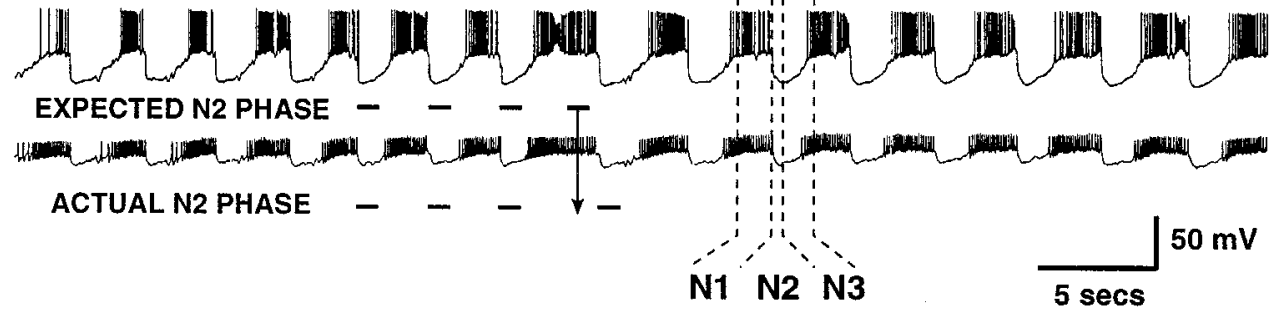

\section{Cii Depolarization}

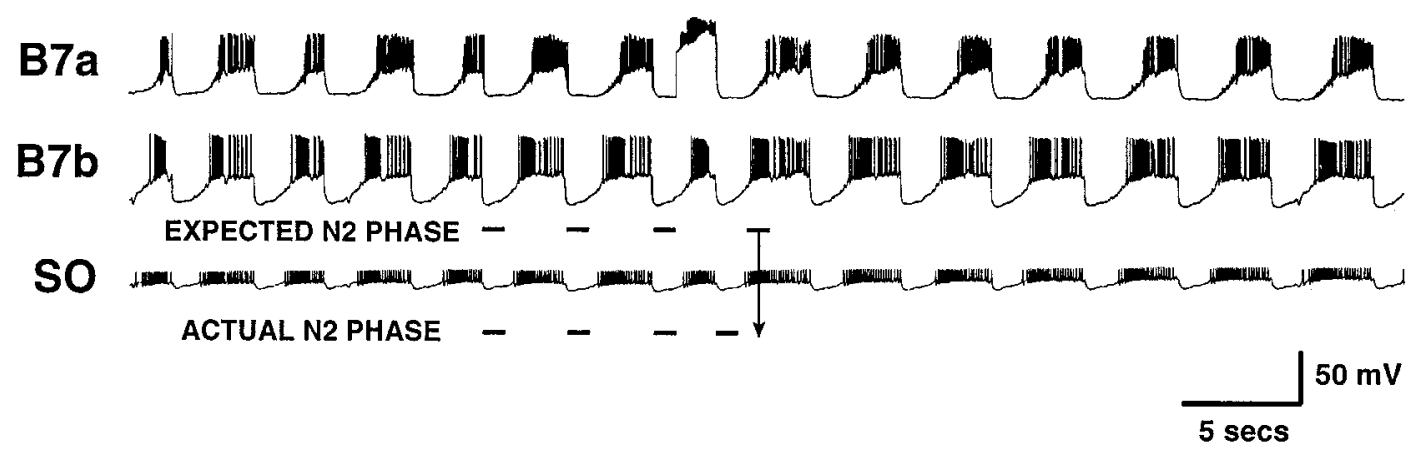

Figure 6. Resetting a spontaneous feeding rhythm by manipulating B7a spike activity. $A$, In an SO-driven feeding rhythm the N1M is driven into activity by the facilitating $\mathrm{SO} \rightarrow \mathrm{N} 1 \mathrm{M}$ excitatory synaptic connection. This elicits individual synaptic potentials (arrow), which eventually trigger a burst of spikes in the N1M. Spike activity in B7a contributes to this buildup through the B7a $\rightarrow$ N1M electrotonic synapse. Hyperpolarization of the B7a slows this buildup and reduces the frequency of the pattern. $B$, Depolarization of $\mathrm{B} 7 \mathrm{a}$ accelerates the buildup to plateau in the N1M, and the frequency of the rhythm is increased. $C$, Effects of briefer B7a activity changes on an ongoing SO-driven fictive feeding pattern. The noncoupled B7b also is recorded to monitor the effects on the rhythm. $\mathrm{Ci}$, Hyperpolarization of B7a preventing one whole burst prolongs the duration of the cycle and delays the whole rhythm. Cii, Brief depolarization of B7a advances the next cycle by accelerating the onset of N2 inhibition on both SO and B7b. The B7a recording was made through a single current-passing electrode; therefore, the deflection in the trace does not reflect the actual size of the membrane potential shift. However, the depolarizing current was the same as in the experiments that were performed to demonstrate coupling between B7a and N1M, and the spike frequency in the evoked burst was in the range of spike frequencies observed in CPG-driven bursts. In both experiments the expected and actual N2 phases are marked before and after B7a manipulation. The vertical arrows show the phase shift that follows the perturbation (see Results for further explanation).

revealed a single peripheral projection to the postbuccal nerve and extensive dendritic branching restricted to the ipsilateral buccal ganglion. Overlapping neuritic processes of B10 and N2d cells shown by double dye fills suggested that the site of the electrotonic junction was in the buccal neuropile (Figs. 7D, 4B).

Although it was shown previously that B10 is excited phasically in both the N1 and N2 phase of feeding (Rose and Benjamin, 
1981a), there was no experimental evidence to show that it was a motoneuron. However, the peripheral axonal projection described above did indicate that B10 innervated the buccal mass. Using a preparation in which the CNS was left attached to the buccal mass by the postbuccal nerve alone, we found that it was possible to make simultaneous recordings from B10 and buccal mass muscles to provide more direct evidence for motoneuronal function. Experiments $(n=2)$ showed that a steady depolarization in $\mathrm{B} 10$ resulted in contractions of the radula tensor muscle (Fig. 7Fi). In addition, during CPG-driven B10 bursts in a spontaneous fictive feeding rhythm, contractions in the radula tensor muscle also were observed (Fig. 7Fii). Previous work has demonstrated that this muscle shows strong electromyographic activity during the retraction phase of feeding, when B10 fires strongly because of strong N2-driven excitation (Rose and Benjamin, 1979). In addition, B10 is the only known CPG follower cell that both fires in the retraction phase and projects to the radula tensor muscle through the postbuccal nerve, the only connection left intact in the preparations in which the role of B10 as a motoneuron was assessed. This, together with the new, more direct recording evidence, verifies the previous assumption that B10 is a motoneuron of the feeding network.

Recordings of the B10 cell also were made with protraction and swallow phase CPG interneurons (N1M, N3t, N3p), but no synaptic connections were found, indicating that the coupling is restricted to rasp phase cells.

\section{B10 role in pattern generation}

Experiments were performed to establish whether the $\mathrm{B} 10 \rightarrow \mathrm{N} 2 \mathrm{~d} / \mathrm{N} 2 \mathrm{v}$ electrotonic connection could contribute to $\mathrm{N} 2 \mathrm{~d} /$ $\mathrm{N} 2 \mathrm{v}$ firing and therefore to rhythmic activity in the whole CPG. In the example shown in Figure $7 E$, artificially depolarizing the B10 by $17.7 \mathrm{mV}$ to fire at 35 spikes/sec, both values within the normal physiological range of this cell type in a fictive feeding rhythm, triggered plateaus in the $\mathrm{N} 2 \mathrm{v}$ and depolarized $\mathrm{N} 2 \mathrm{~d}$ cells. However, this was rare $(n=2)$, and more typically subthreshold potentials were seen $(n=5)$.

To determine the contribution to pattern generation provided by the B10, we manipulated membrane potential and firing activity in this neuron within its normal physiological range during SO-driven feeding rhythms. In the example shown in Figure $8 A$, hyperpolarizing the B10 to prevent spiking for approximately seven cycles interrupted the whole fictive feeding rhythm for as long as the hyperpolarization was maintained. Although the N2vs were not recorded in this experiment, activity in $\mathrm{N} 2 \mathrm{v}$ as well as N2d was likely to be suppressed by B10 hyperpolarization because of the loss of the strong hyperpolarizing wave on the SO. This is known to be caused by an $\mathrm{N} 2 \mathrm{v} \rightarrow \mathrm{SO}$ inhibitory synapse (Brierley et al., 1997b). Unlike hyperpolarization, a burst of depolarizing current-induced B10 spikes (frequency 29.4 spikes/ sec, within the physiological range) in an SO-driven rhythm had little influence on the ongoing rhythm, even when maintained for longer than the duration of CPG-driven bursts in B10 (Fig. 8B). The B10 depolarized the $\mathrm{N} 2 \mathrm{~d}$ and presumably the $\mathrm{N} 2 \mathrm{v}$ (not recorded), but this was insufficient to trigger a plateau. In conclusion, it appears that the B10 cells play a contributory role to activity of the N2 retraction phase neurons, but this role is less significant to overall pattern generation than the B7a cells.

\section{B4CL/B4 motoneuron coupling with the swallow phase interneurons, N3p and N3t}

Previous work has shown that there are two physiologically defined types of B4 neurons, a pair of so-called main B4 cells and a group of so-called B4 cluster (B4CL) neurons (approximately six cells on each side) (Benjamin and Rose, 1979; Rose and Benjamin, 1981a). Other work has demonstrated that there are also two physiologically different types of N3 (swallow) phase CPG cells, N3 phasic (N3p) and N3 tonic (N3t) (Elliott and Benjamin, 1985a) (Fig. 9A).

The N3p cells tend to fire earlier in the feeding cycle than the N3t cells, toward the end of the N2 (rasp) phase and through the start of the swallow phase (Yeoman et al., 1995) (Fig. 9A). This coincides with activity in the B4CL late rasp phase motoneurons, and spikes during the B4CL burst are interrupted by the N3p $\rightarrow$ B4CL inhibitory synaptic input (Benjamin and Rose, 1979; Rose and Benjamin, 1981a). The N3t cells fire entirely during the swallow phase, and this coincides with activity in the $\mathrm{B} 4$ cells (Fig. 9A).

On the basis of the results from the other $\mathrm{CPG}$-motoneuron connections, it was predicted that the $\mathrm{B} 4 \mathrm{CL} \rightarrow \mathrm{N} 3 \mathrm{p}$ cells and the $\mathrm{B} 4 \rightarrow \mathrm{N} 3 \mathrm{t}$ cells would be coupled electrotonically. This was found to be the case (Fig. 9B). Hyperpolarizing or depolarizing a B4CL cell produced corresponding responses on an N3p cell $(n=3$; maximum DC coupling coefficient, $16 \%$ ), and the same occurred with a B4 and N3t cell $(n=3$; maximum DC coupling coefficient, $31 \%$ ). Both the firing rate of the current-evoked burst of spikes (24.5 spikes/sec) and the size of the underlying depolarization $(18.8 \mathrm{mV})$ in B4 (Fig. 9B), which turned out to be important in pattern generation (see below), were within the physiological range (from $3.8 \pm 0.7$ to $33.5 \pm 3.5$ spikes/sec and from $8.5 \pm 0.6$ to $19.0 \pm 0.6 \mathrm{mV}$, respectively). In the case of the $\mathrm{B} 4 \mathrm{CL} \rightarrow \mathrm{N} 3 \mathrm{p}$ the electrotonic coupling persisted in a HiLo+EGTA saline, providing further evidence for an electrotonic junction (Fig. 9C, $n=3)$. Testing the $\mathrm{N} 3 \mathrm{p} \rightarrow \mathrm{B} 4 \mathrm{CL}$ connection revealed a more complex response that had both chemical and electrotonic components (Fig. 9D). Previous work has shown that the N3p provides an inhibitory input via a chemical synapse to the B4CL neurons. This showed itself as an initial fast hyperpolarizing response when N3p starts to fire (Fig. 9Di). However, this was followed by a depolarization that probably reflected the conjoint electrotonic synaptic connection. This electrotonic component was exposed when the same preparation was bathed in HiLo+EGTA saline $(n=2)$. Then a purely depolarizing potential followed N3p spike activity (Fig. 9Dii). Spikes were difficult to generate in the N3p under these zero calcium conditions, but they still occurred at the beginning of the depolarizing current pulse. Hyperpolarization of $\mathrm{N} 3 \mathrm{p}$ in the same experiment showed a hyperpolarizing voltage response in the B4CL cell in both normal and HiLo+EGTA saline, presumably because of the purely electrotonic nature of the communication with negative current. In the absence of dye coupling, a final piece of evidence for potential direct synaptic contacts between the N3p and B4CL cells is double dye filling $(n=9)$. Like the other cells there are plenty of sites between the closely apposed N3p/B4CL neurites where a synaptic connection could occur (Figs. 9E, 4Ci, Cii). Postinhibitory rebound was considered by Benjamin and Elliott (1989) to be the main way that the N3ps activated the B4CL cells, but these new data showing a conjoint chemical/electrotonic synapse from N3p to B4CL cells with a delayed electrotonic activation suggest that this also contributes to B4CL excitation in the Lymnaea feeding system.

Dual recordings from a variety of late rasp/swallow phase motoneurons and interneurons demonstrated that the coupling was not mutually exclusive between these motoneuron-interneuron cell types, and B4 cells also were coupled to N3p cells and, 
A

B10

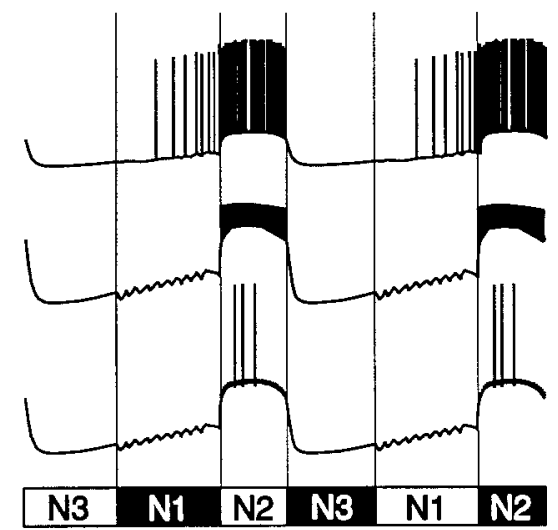

C i normal ii hilo+Egta

N2d

B10
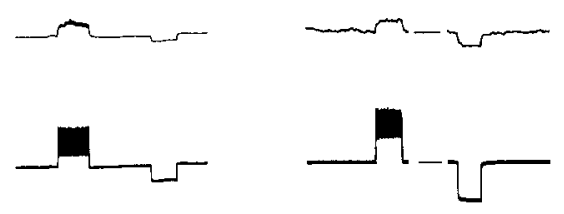

I(B10) 几ே

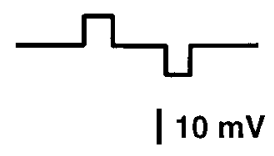

$5 \overline{\operatorname{secs}} \mid 50 \mathrm{mV}$

B
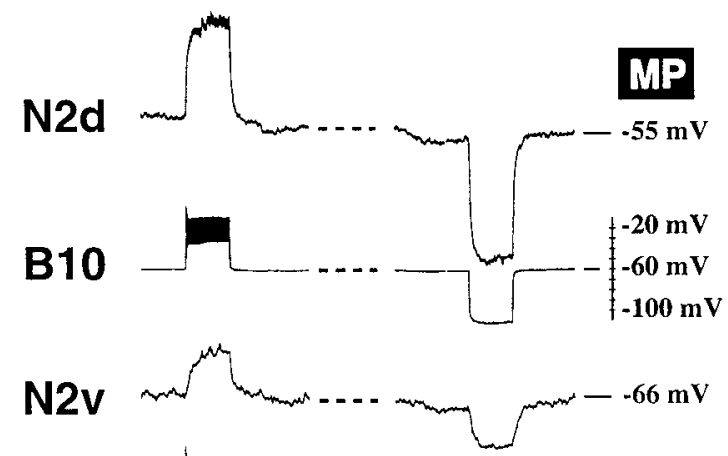

B10

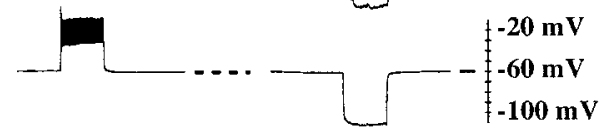

I(B10) $几$

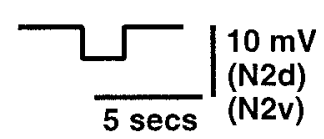

D
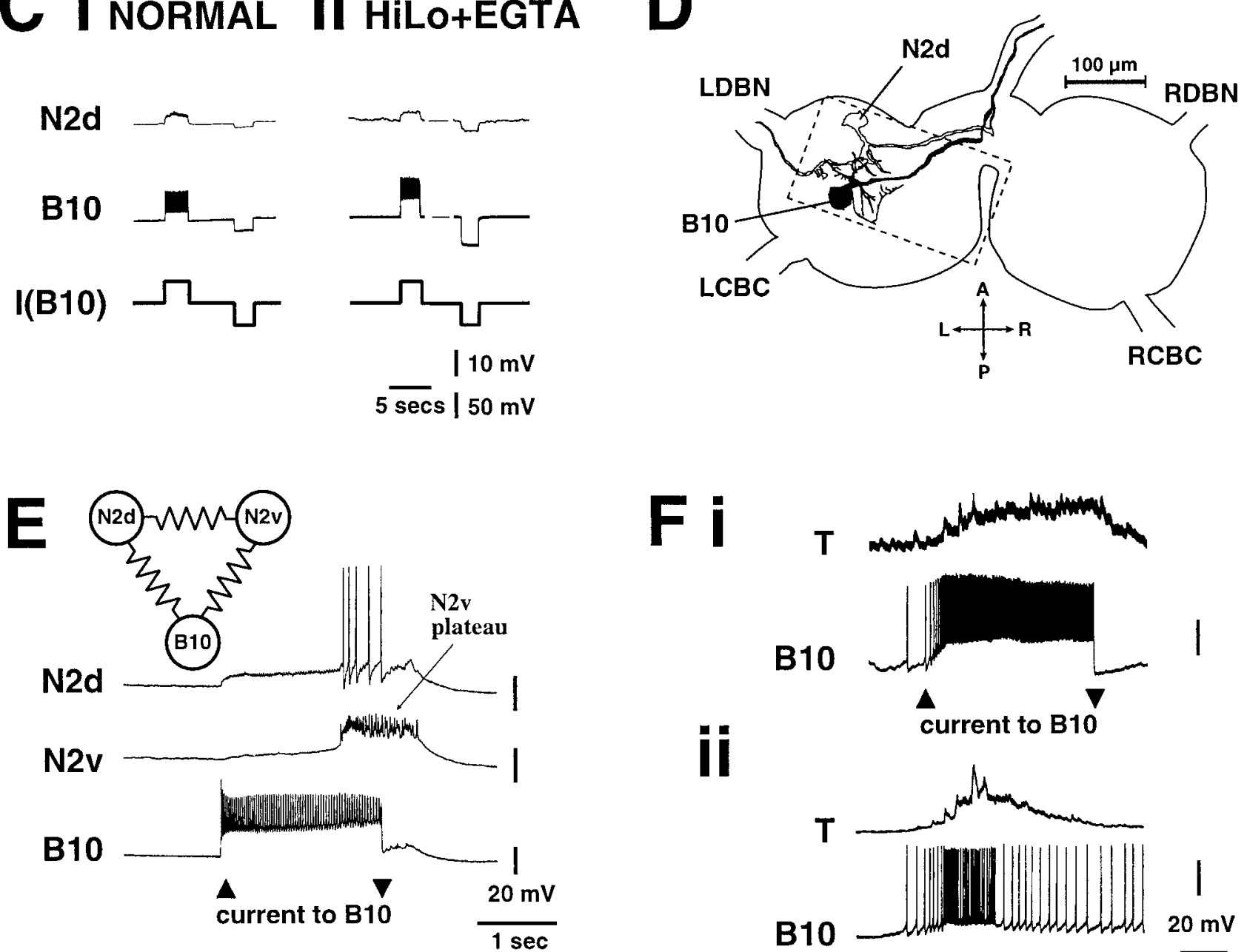

$\mathbf{F i}$
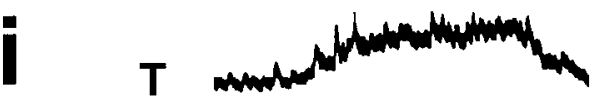

B10

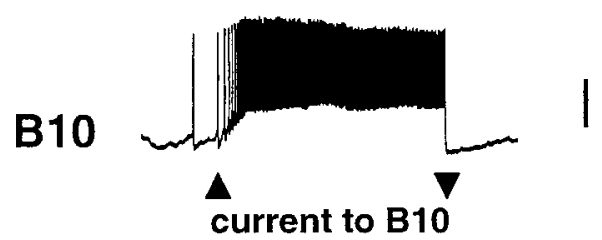

ii

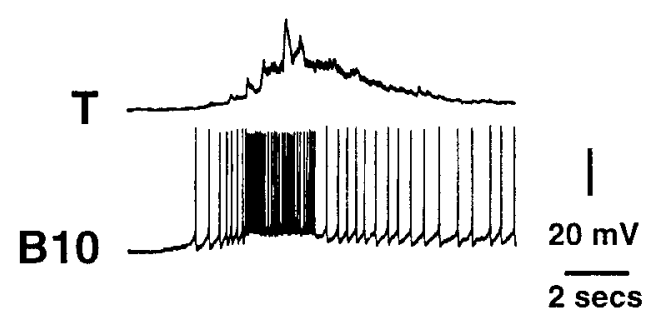

Figure 7. Electrotonic coupling between the rasp phase B10 motoneuron and the N2d/N2v retraction phase CPG interneurons. $A$, Diagram showing the firing pattern of the B10, N2v, and N2d neurons in a CPG-driven fictive feeding rhythm. All three neurons fire together in the N2 (rasp) phase. The $\mathrm{N} 2$ cells are inhibited during N3 and receive a biphasic input during the N1 phase. The B10 neurons are inhibited during N3 and are weakly excited during the N1 phase. $B$, Depolarizing or hyperpolarizing current injected into B10 produces similar, although attenuated, voltage changes in both the $\mathrm{N} 2 \mathrm{~d}$ and N2v. Membrane potential $(M P)$ changes in B10 were measured through a second voltage recording electrode so that coupling coefficients could be determined accurately. $C$, The $\mathrm{B} 10 \rightarrow \mathrm{N} 2 \mathrm{~d}$ connection $(\mathrm{Ci})$ is retained in HiLo+EGTA saline (Cii), which blocks (Figure legend continues.) 


\section{A Hyperpolarization}

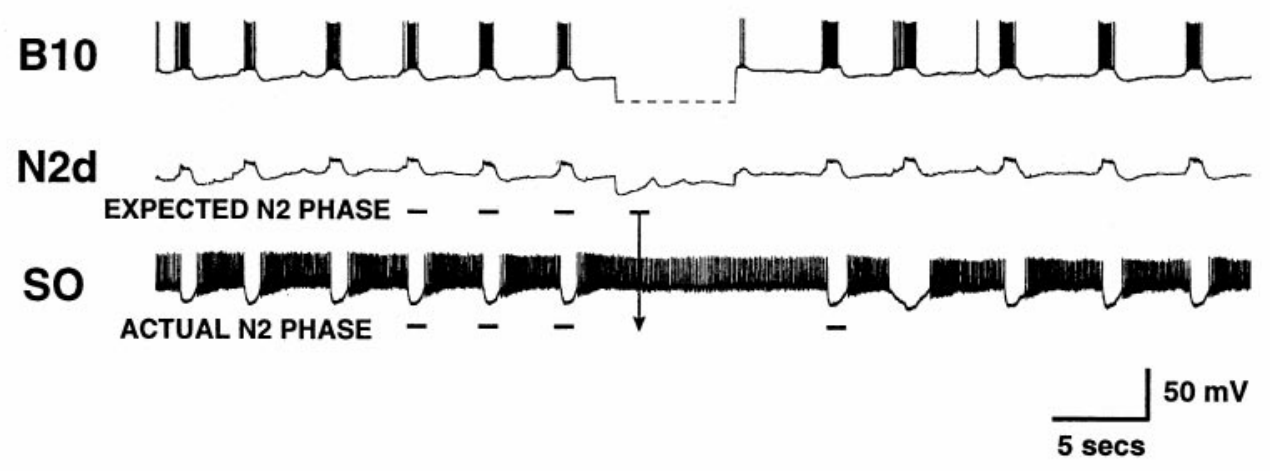

\section{B Depolarization}

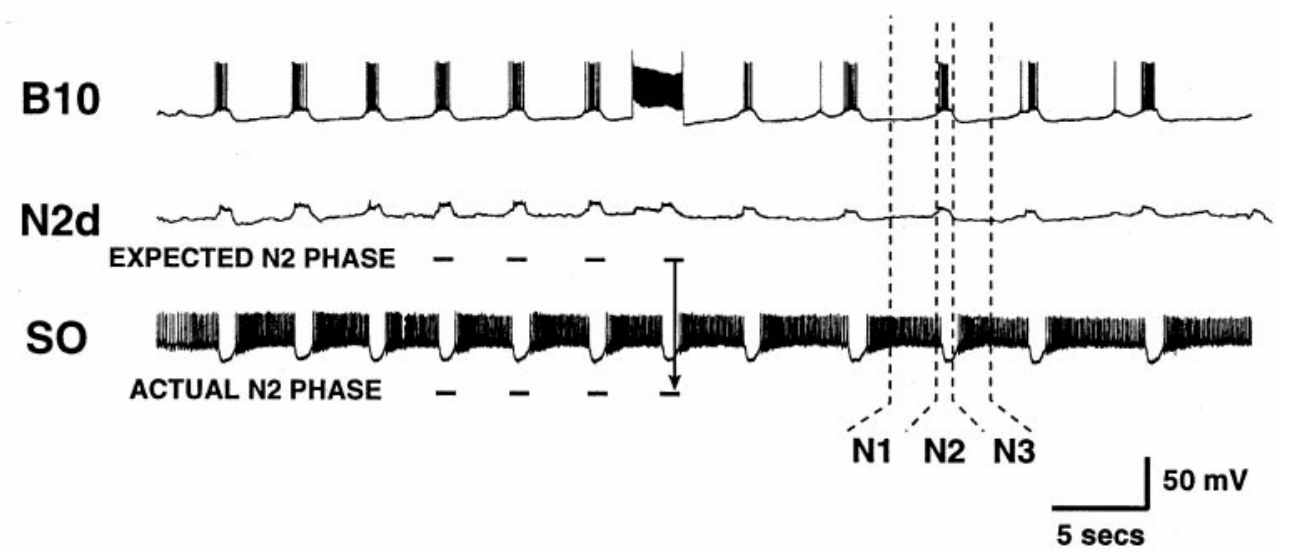

Figure 8. Resetting an ongoing SO-driven fictive feeding rhythm by manipulation of B10 activity. A, Hyperpolarization of B10 prevents the expected $\mathrm{N} 2$ phase of the feeding cycle and delays the rhythm. $B$, Depolarization of B10 has only a small effect on the ongoing rhythm, accelerating the buildup to N2d plateau and slightly advancing the next cycle. In both experiments the expected and actual N2 phases are marked before and after B10 manipulation. The vertical arrows show the phase shift that follows the perturbation.

conversely, B4CL to N3t cells. This cross-phase coupling appeared to be weaker, although there were not sufficient data for statistical analysis. However, no coupling was found between N3t and N3p CPG interneurons and any other motoneuron cell types, showing that the coupling was only between retraction phase neurons and not those involved with protraction. There is usually an overlap in the activity of $\mathrm{N} 3 \mathrm{p} / \mathrm{N} 3 \mathrm{t}$ in a feeding rhythm and some coupling among all of the cells in the B4CL/B4 motoneuron complex, and the CPG interneurons might play a role in this. This might explain the lack of exclusivity of motoneuron-interneuron coupling in the late rasp/swallow phase cells. It is still significant that both the coupling coefficient and the effect of the coupling were much stronger in the case of the $\mathrm{B} 4 \rightarrow \mathrm{N} 3 \mathrm{t}$ (swallow phase) than between the B4CL and N3p (late rasp phase) cells. In the former case, bursts of B4-evoked spikes at physiological rates usually drove spikes in the N3t, whereas this never occurred in the case of the B4CL $\rightarrow$ N3p cells (Fig. 9B). This can be explained by the finding that, in addition to the stronger $\mathrm{B} 4 \rightarrow \mathrm{N} 3 \mathrm{t}$ coupling, the $\mathrm{N} 3 \mathrm{t}$ cells commonly have more positive resting potentials than the N3p cells (see Fig. 9B), whereas the spike threshold is approximately the same for both cell types $(\sim 40 \mathrm{mV})(\mathrm{K}$. Staras, unpublished observations).

$\leftarrow$

chemical synapses, confirming the electrotonic nature of the connection. Note that the B10 recordings were made through a single current-passing electrode, and so the presence of coupling could be established but could not be assessed quantitatively. $D$, Diagrammatic reconstruction of joint fills of the B10 and N2d with 5-CF and MPTS, respectively. The B10 has a single axon that crosses the buccal neuropile and exits the ganglia via the postbuccal nerve. The N2d has axonal projections in both the postbuccal nerve and the ipsilateral dorsobuccal nerve. The extensive intermingling of neuritic processes from these two neurons suggests that the site of the electrotonic coupling is in the buccal neuropile (for high-magnification details of the area in the rectangle, see Fig. $4 B$ ). E, Depolarizing the B10 motoneuron occasionally can trigger spikes in both N2v and N2d CPG. In this example the activation of B10 depolarizes both N2-type interneurons via electrotonic coupling. This leads to the activation of a full plateau potential in N2v (see Brierley et al., 1997a) and spikes in the N2d, which are driven by both B10 and N2v cells. The electrotonically coupled network is shown in the schematic diagram. $F$, Motoneuronal function of B10 demonstrated by dual recordings from B10 and the muscle it innervates. $F i$, Spike activity in B10, driven by a depolarizing stimulus, leads to the contraction of the radula tensor muscle (T). Fii, In the same preparation, during spontaneous fictive feeding, $\mathrm{CPG}$-driven bursts of spikes in B10 also are followed by the contraction of the radula tensor muscle. 


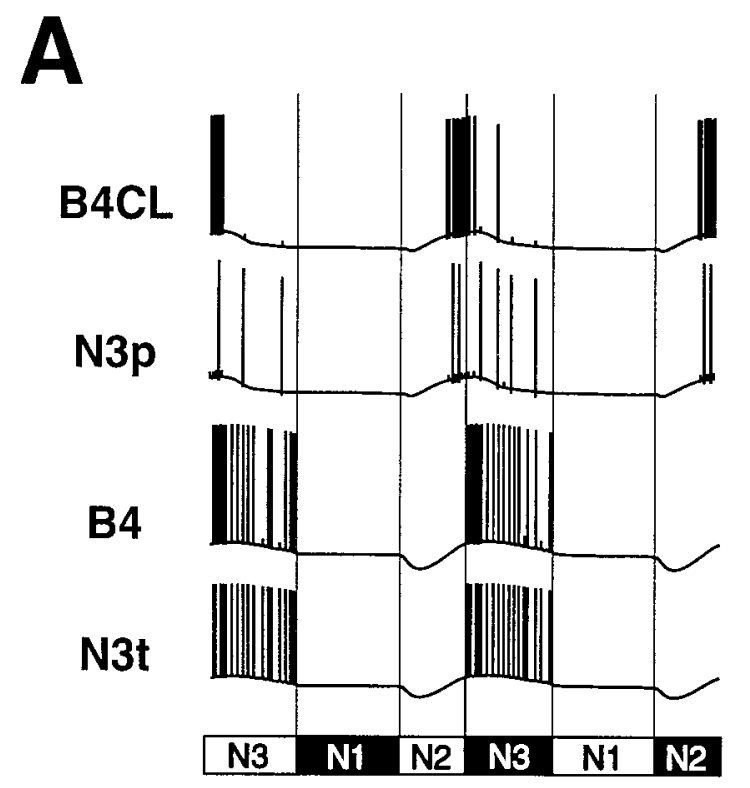

\section{I normal ii hilo+egta}

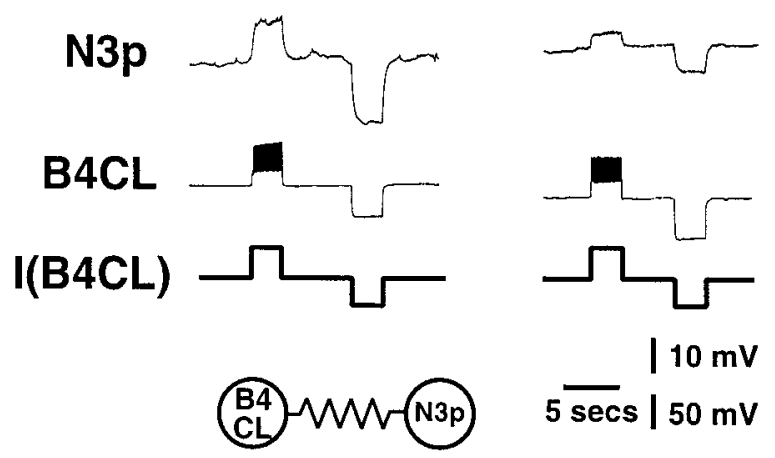

E

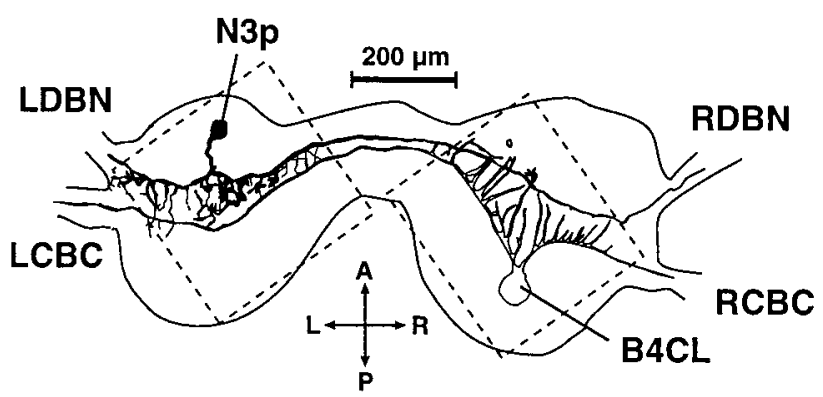

B

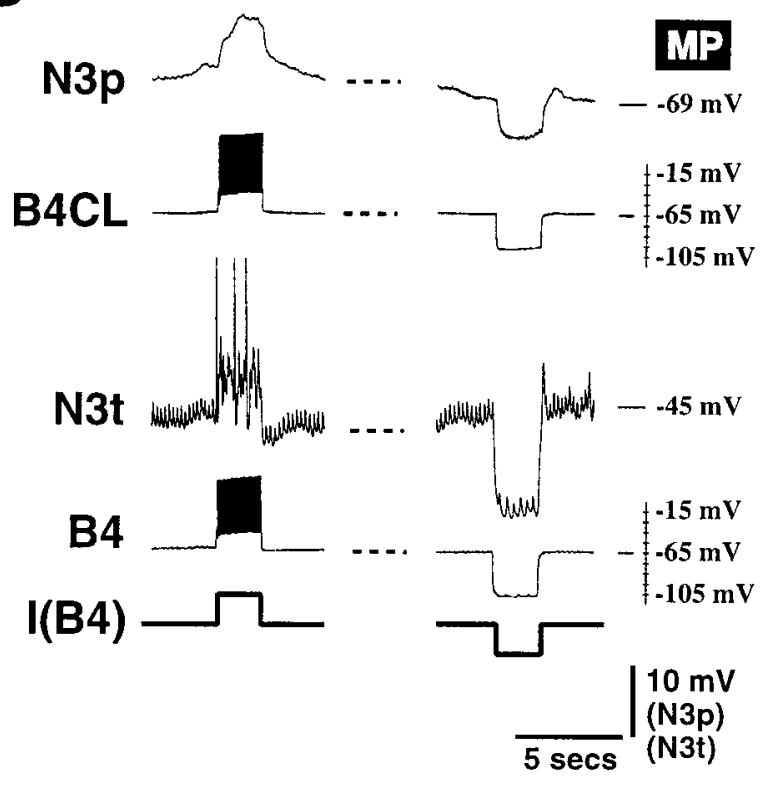

D i normal ii hilo+egta

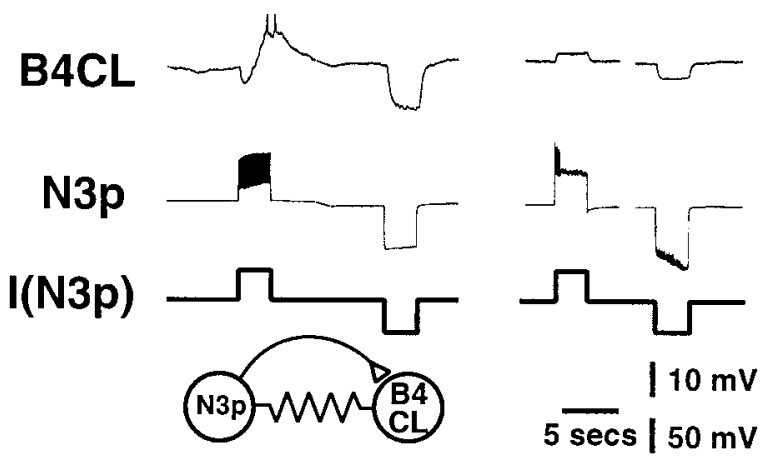

Figure 9. Electrotonic coupling between the rasp/swallow phase B4CL and $\mathrm{B} 4$ motoneurons and the N3p and N3t CPG interneurons. $A$, Diagram showing the typical firing pattern of the B4CL, N3p, B4, and N3t neurons in a CPG-driven fictive feeding rhythm. The B4CL and N3p cells fire together at the end of the N2 (rasp) phase and continue firing into the N3 phase. The B4 and N3t cells fire together in the N3 (swallow) phase. All of the neurons are inhibited during $\mathrm{N} 1$ and the start of the N2 phase. $B$, Depolarizing or hyperpolarizing current injected into B4CL produces similar, although attenuated, subthreshold voltage changes in the N3p. The B4 motoneurons show a similar electrotonic connection with the N3t but depolarizing current often can trigger full spikes in N3t. Membrane potential $(M P)$ changes in B4CL and B4 were measured through a second voltage recording electrode so that coupling coefficients could be determined accurately. $C$, The $\mathrm{B} 4 \mathrm{CL} \rightarrow \mathrm{N} 3 \mathrm{p}$ connection seen in normal saline $(\mathrm{Ci})$ is retained in HiLo+EGTA saline ( $\mathrm{Cii}$ ), which blocks chemical synapses, confirming the electrotonic nature of the connection. $D$, The

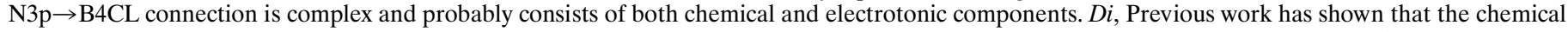

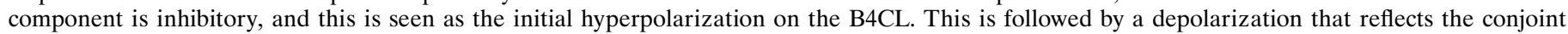

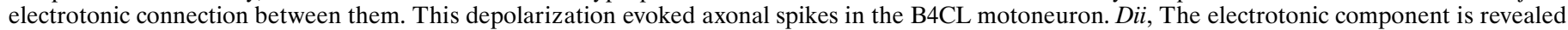

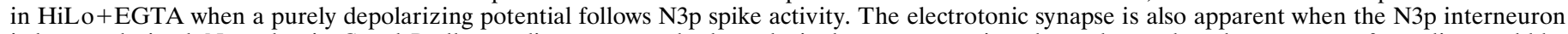

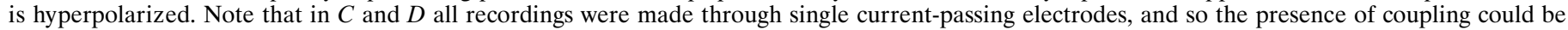

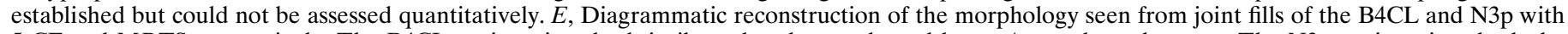

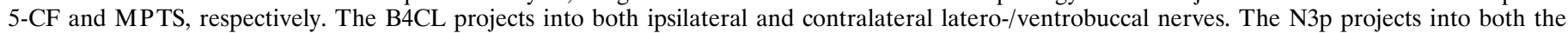

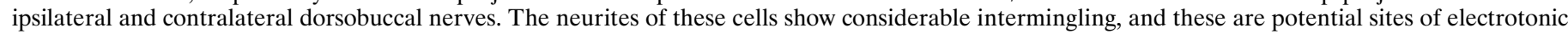
junctions (for high-magnification details of the areas in the rectangles, see Fig. 4Ci, $\mathrm{Cii}$ ). 


\section{The B4 motoneurons potently inhibit the N1M interneuron through the indirect $\mathrm{B} 4 \rightarrow \mathrm{N} 3 \mathrm{t} \rightarrow \mathrm{N} 1 \mathrm{M}$ pathway}

Unexpectedly, the main effect of manipulating B4 activity on pattern generation was on an interneuron active in a completely different phase of the feeding rhythm, the protraction phase CPG cell, N1M. Strong activation of a single B4 motoneuron produced intense inhibition in the protraction phase interneuron N1M. The strength of the inhibition was quite variable in different preparations but in the majority of cases ( $n=7$ of 9) was sufficient to suppress activity in a depolarized spiking N1M (Fig. 10 Ai). The details of the IPSPs recorded on N1M after B4 depolarization are seen more clearly when the time base is expanded (Fig. 10Aii). The frequency of the current-induced burst of spikes in B4 in this figure (10.8 spikes/sec) was within the normal frequency range seen in fictive feeding rhythms.

Further experiments showed that this connection was likely to be mediated through the $\mathrm{B} 4 \rightarrow \mathrm{N} 3 \mathrm{t}$ electrotonic coupling and the previously demonstrated N3t $\rightarrow \mathrm{N} 1 \mathrm{M}$ monosynaptic chemical synapse (Elliott and Benjamin, 1985a). Direct evidence for the pathway is shown in Figure 10B, in which the B4, N3t, and N1M cells were recorded at the same time. Here, as in the example shown in Figure 10Aii, the frequency of the current-induced burst of spikes in B4 (21.0 spikes/sec) was again within the normal frequency range seen in fictive feeding rhythms; this was sufficient to drive spike activity in the N3t via the B4 $\rightarrow$ N3t electrotonic synapse. Each spike in the N3t cell produced unitary 1:1 IPSPs in the N1M cells, making it unlikely that other cells, potentially also driven by B4, contribute to this effect. There are no changes in membrane potential or components of the N1M synaptic response that correlate with B4 depolarization or spike activity so that the B4 effects are unlikely to be attributable to a direct B4 $\rightarrow$ $\mathrm{N} 1 \mathrm{M}$ inhibitory chemical connection. In some preparations the $\mathrm{N} 3 \mathrm{t}$ cells were firing spontaneously, providing a tonic inhibitory input to N1M. In these cases, when a quiescent B4 was hyperpolarized further, the activity in N3t was suppressed and the N1M was released from inhibition (Fig. 10C). The spontaneous N1M burst occurring during the hyperpolarization of B4 could be interrupted by a burst of spikes in N3t evoked by brief depolarization. This showed the profound contribution B4 can make to the state of firing in interneurons of the CPG system through its electrotonic coupling to N3t.

Using a buccal mass-CNS preparation, we also established the dual role of the $\mathrm{B} 4$ as both a conventional motoneuron and as a cell providing inputs to $\mathrm{CPG}$ interneurons. The experiment involved simultaneous intracellular recording from the B4 motoneuron, the buccal mass muscle it is known to innervate (the anterior jugalis; Benjamin and Elliott, 1989), and the N1M interneuron. Depolarization of the B4 elicited 1:1 excitatory junction potentials (EJPs) on the anterior jugalis muscle of the buccal mass $(n=4)$ and simultaneous IPSPs on the N1M occurring through activation of the N3t (Fig. 10D; B4 spike frequency is 14 spikes/sec, within the normal frequency range seen in fictive feeding rhythms). The B4 cells thus appear to have several roles in the feeding network. They act as motoneurons for the anterior jugalis muscle. They also have CPG effects by providing excitatory drive to the $\mathrm{N} 3 \mathrm{t}$ cells via electrotonic synapses and have strong indirect effects on a second type of CPG cell, the N1M via the $\mathrm{N} 3 \mathrm{t} \rightarrow \mathrm{N} 1 \mathrm{M}$ inhibitory chemical synapse. These connections are summarized in Figure $10 \mathrm{E}$. The role of the indirect $\mathrm{B} 4 \rightarrow \mathrm{N} 1 \mathrm{M}$ connection in pattern generation will be considered next.

\section{B4 role in pattern generation}

The pattern-generating contribution made by the $\mathrm{B} 4 \rightarrow \mathrm{N} 3 \mathrm{t}$ electrotonic connection was investigated by manipulating B4 membrane potential and firing activity within its normal physiological range during SO-driven feeding rhythms. The N3t was not recorded directly in these experiments, but the inhibitory inputs on the $\mathrm{N} 1 \mathrm{M}$ attributable to the $\mathrm{N} 3 \mathrm{t} \rightarrow \mathrm{N} 1 \mathrm{M}$ synaptic connection can be identified easily after extensive previous experimental characterization (see Benjamin and Elliott, 1989). In Figure $11 \mathrm{Ai}$, a control rhythm is shown in which no B4 perturbation is performed. The normal level of $\mathrm{N} 3 \mathrm{t}$ synaptic inputs appearing on the $\mathrm{N} 1 \mathrm{M}$ during the buildup to the protraction phase is shown in Figure 11Aii. In Figure $11 \mathrm{Bi}$, a $2 \mathrm{sec}$ pulse of hyperpolarizing current injected into the B4 was able to trigger the next feeding cycle prematurely. This was attributable to the removal of the $\mathrm{N} 3 \mathrm{t} \rightarrow \mathrm{N} 1 \mathrm{M}$ inhibition that normally delays the recovery of N1M during the N3/swallow phase of the feeding rhythm. The absence of N3t IPSPs and the steeper rise of the depolarization before the $\mathrm{N} 1$ plateau is shown in the higher gain recording of Figure 11Bii. Conversely, a burst of spikes [spike frequency 34.6 spikes/sec, within the physiological range; duration $2.6 \mathrm{sec}$, not significantly different from the mean duration $(2.4 \pm 0.2 \mathrm{sec})$ of five CPGdriven bursts preceding it] evoked in B4 during an ongoing rhythm delayed the feeding pattern by presumably exciting the $\mathrm{N} 3 \mathrm{t}$ (Fig. 11Ci). The number of $\mathrm{N} 3 \mathrm{t} \rightarrow \mathrm{N} 1 \mathrm{M}$ unitary IPSPs appearing on the $\mathrm{N} 1 \mathrm{M}$ is increased (Fig. $11 \mathrm{Cii}$ ), and these delay the buildup to the plateau phase of firing. These experiments demonstrate that the B4 plays a role in pattern generation via its electrotonic connection with the N3t.

\section{Glandular motoneurons are not connected electrotonically to CPG interneurons}

Extensive tests were made for synaptic connections between CPG interneurons and motoneurons generally considered to have a motor role in controlling glandular secretion or contractions of the gut. These motoneurons were the B1, provisionally classified as a salivary gland motoneuron, the B2, a gut motoneuron, and $\mathrm{B} 3$, a rasp phase motoneuron that may be involved in control of glandular activity in the gut (Benjamin et al., 1979). In general, no synaptic connections, either chemical or electrotonic, were found between these motoneurons and CPG interneurons active in the same or different phases of the feeding cycles.

\section{DISCUSSION}

In this paper we have provided detailed physiological evidence for the existence of new feedback pathways from identified motoneurons to specific interneurons of the CPG in the Lymnaea feeding system, an important invertebrate model of behavioral rhythm generation (Benjamin and Elliott, 1989). We showed that synaptic interactions between motoneurons and interneurons are important in rhythm generation so that both interneurons and motoneurons are essential components of the pattern-generating network. These results provide further evidence for the distributed nature of the Lymnaea feeding network (Yeoman et al., 1995), superseding an earlier hierarchical model (Benjamin, 1983). This, together with work on other CPG systems, has important theoretical consequences in consideration of the general design of circuits underlying adaptive behavior (for review, see Morton and Chiel, 1994).

The connections underlying these feedback pathways take the form of electrotonic synapses between motoneurons and CPG interneurons. Motoneurons with electrotonic connections with 

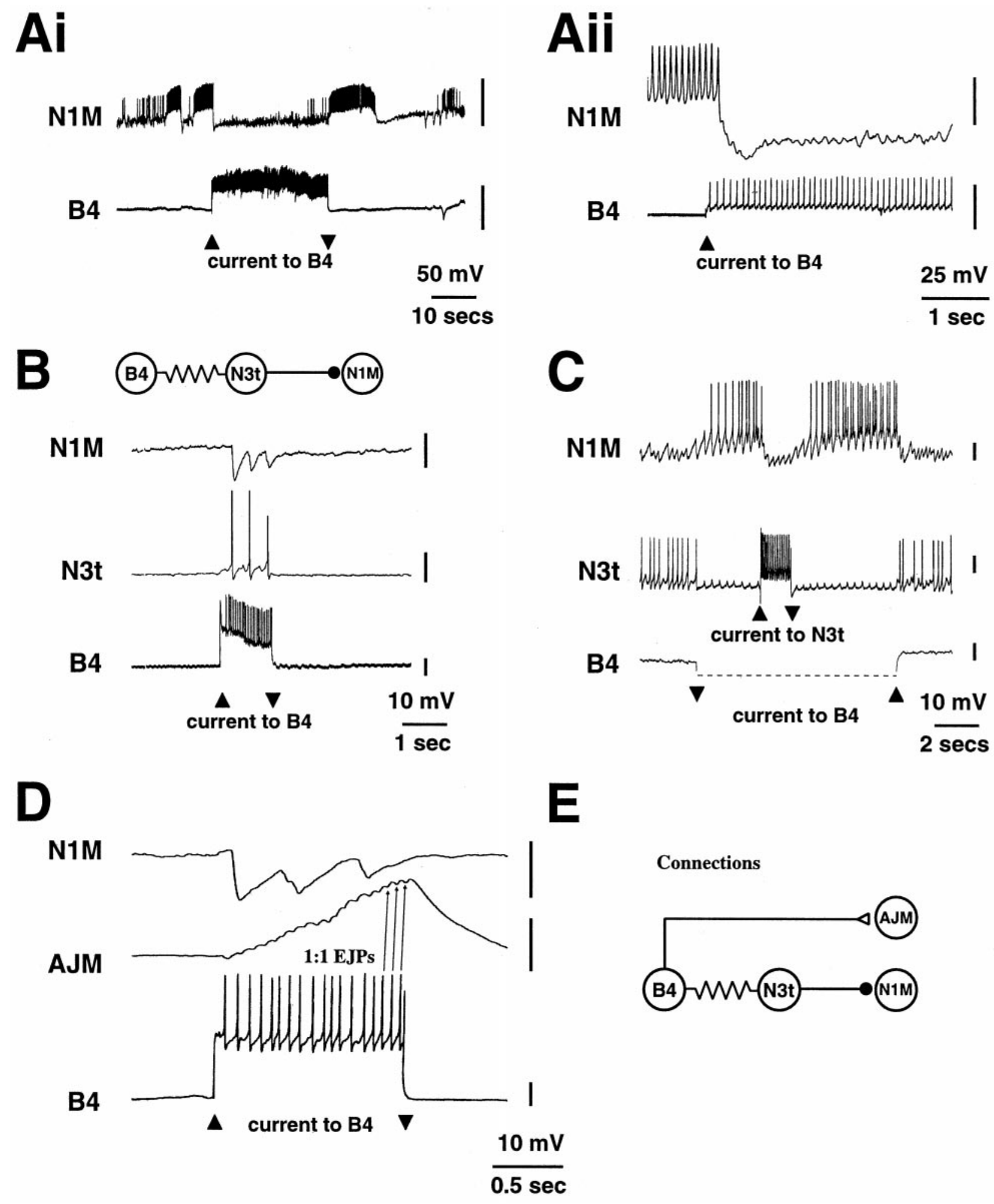

Connections

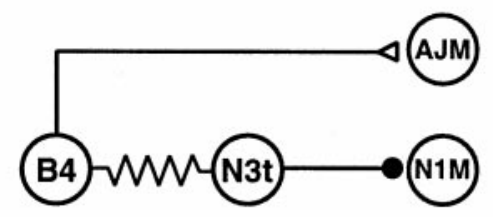

Figure 10. Dual role of the B4 cell as a motoneuron and a provider of inputs to CPG interneurons. Ai, Activation of B4 produces intense inhibition (expanded in $A i i$ ), which suppresses spontaneous bursting activity in the protraction phase CPG interneuron N1M. B, Evidence that this is likely to be attributable to the indirect $\mathrm{B} 4 \rightarrow \mathrm{N} 3 \mathrm{t} \rightarrow \mathrm{N} 1 \mathrm{M}$ pathway obtained from simultaneous intracellular recordings of B4, N1M, and N3t. Each spike in the N3t produces unitary IPSPs in the N1M. $C$, Hyperpolarization of B4 can release the N1M interneuron from the inhibition caused by tonic firing in N3t. A brief burst of spikes in N3t during this B4 suppression briefly interrupts firing activity in N1M. After the repolarization of B4 to resting potential, the $\mathrm{N} 3 \mathrm{t}$ cell is released from inhibition; as a result, N1M spike activity is suppressed again. $D$, Simultaneous recording from the N1M, the swallow phase anterior jugalis muscle $(A J M)$, and $\mathrm{B} 4$ shows that $\mathrm{B} 4$ has a dual function. A current-induced burst of spikes in B4 evokes unitary 1:1 excitatory junction potentials $(E J P S)$ on the AJM and at the same time inhibits the N1M CPG cell. E, Summary of the synaptic connections of B4. 


\section{Ai Control}

B4

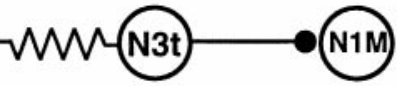

B4

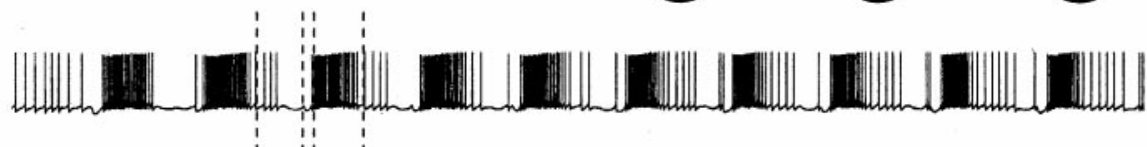

N1M
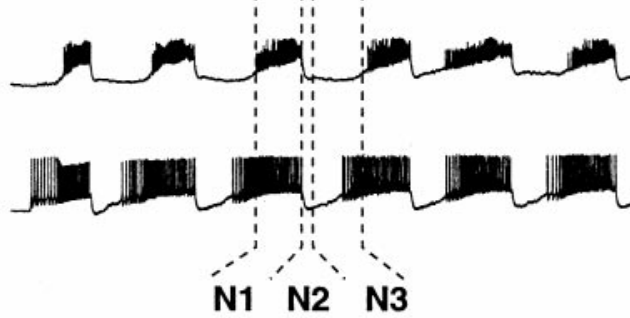

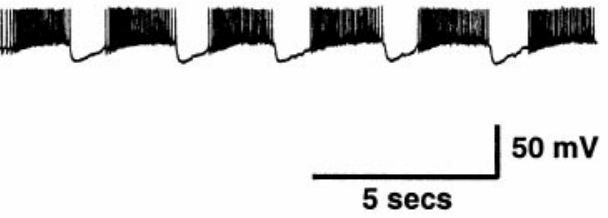

Bi Hyperpolarization

B4

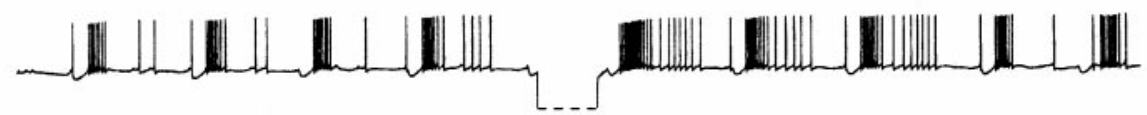

N1M EXPECTED N2 PHASE -

so ACTUAL N2 PHASE -

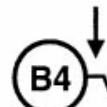

B4
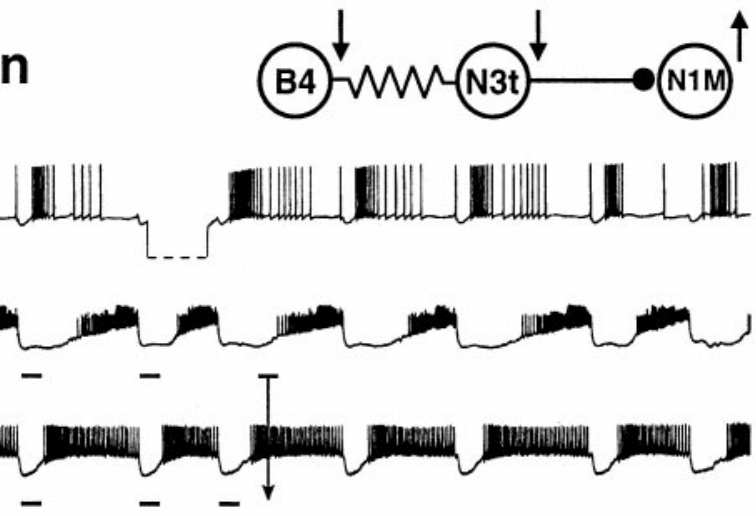

Mrationin

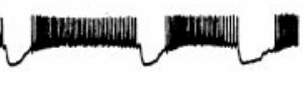

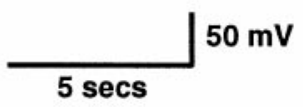

Ci Depolarization

B4
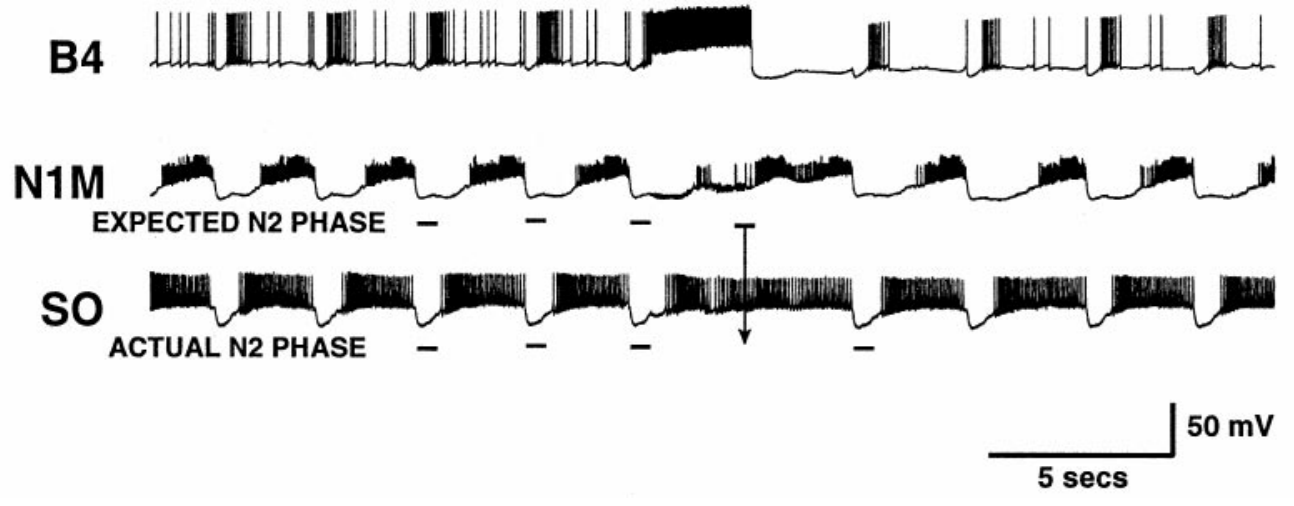

Aii
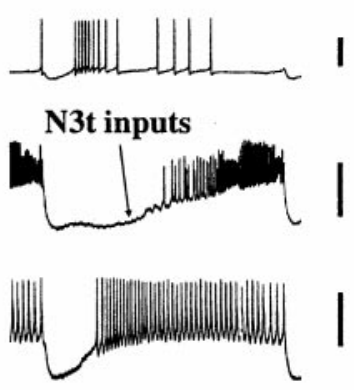

$25 \mathrm{mV}$

2.5 secs
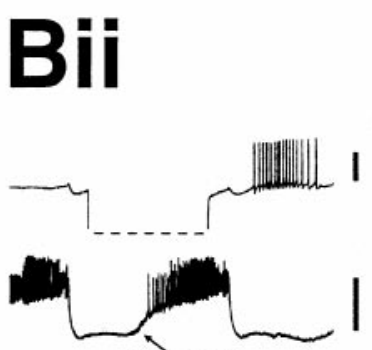

No N3t inputs

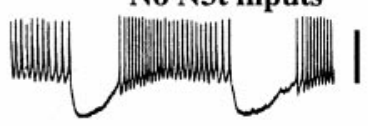

$25 \mathrm{mV}$
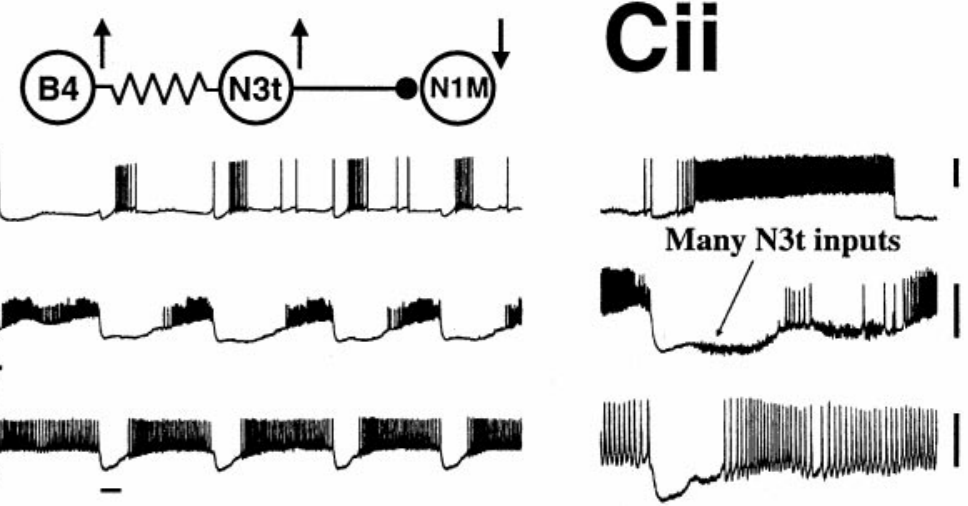

$25 \mathrm{mV}$

2.5 secs

Figure 11. Resetting a feeding rhythm by manipulating B4 spike activity. Ai, Control experiment in which the N1M and B4 show bursting activity in the SO-driven fictive feeding rhythm. Aii, Faster time base and higher gain of $A i$ showing the normal level of N3t inputs appearing on the N1M during the buildup to the protraction phase. Bi, Hyperpolarization of the B4 advances the phase of the SO-driven rhythm. The N1M recovers more rapidly than normal and resets the subsequent rhythm. This is attributable to the reduced duration of the N3t inhibitory inputs on the N1M cell shown in detail in Bii. Ci, Depolarization of the B4 during SO-driven fictive feeding delays the onset of the next feeding cycle and the subsequent fictive feeding rhythm. This is attributable to the increased duration of N3t inhibitory synaptic inputs shown at a higher gain and faster time base in Cii (see Results for further details). The B4 recording was made through a second voltage recording electrode so that the deflection in the trace reflects the actual value of the potential shift $(12.5 \mathrm{mV})$. The direction of the arrows in the synaptic connectivity diagrams indicates the relative change in activity levels in the three neurons (up arrow, increase; down arrow, decrease). 


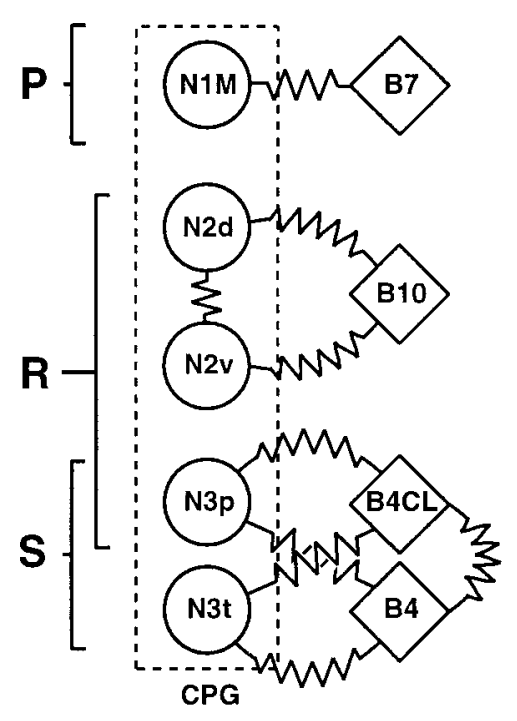

Figure 12. Summary of electrotonic connections between motoneurons and CPG interneurons in the Lymnaea feeding system. Motoneurons are coupled only to interneurons that are active within the same phase of the feeding cycle. Only motoneurons that activate buccal musculature showed these connections. The protraction phase $(P)$ motoneuron $\mathrm{B} 7 \mathrm{a}$ is coupled to the CPG interneuron N1M. The rasp phase $(R)$ motoneuron B10 is coupled to both the N2d and N2v CPG interneurons. N2d and N2v also are coupled electrotonically to each other, suggesting that these three neurons form a single coupled unit. The late rasp/swallow $(R / S)$ phase motoneurons B4CL are coupled to the CPG interneuron N3p. The swallow phase $(S)$ motoneuron B4 is coupled to the N3t interneuron. A cross-coupling also exists between the $R / S$ and $S$ neurons so that they form a larger coupled unit. Note that there are also chemical connections between the CPG interneurons and the motoneurons, which are not shown in this figure (for details of these, see Discussion).

interneurons were found for all three phases of the feeding cycle: protraction (B7a), rasp (B10/B4CL), and swallow (B4). A summary of these connections is shown in Figure 12. The electrotonic coupling was confined to motoneurons and interneurons that were normally active in the same phase of the feeding cycle (protraction, $\mathrm{B} 7 \mathrm{a} \rightarrow \mathrm{N} 1 \mathrm{M}$; rasp, $\mathrm{B} 10 \rightarrow \mathrm{N} 2 \mathrm{~d} / \mathrm{N} 2 \mathrm{v}$; swallow, $\mathrm{B} 4 \rightarrow \mathrm{N} 3 \mathrm{t}$ ). Importantly, the motoneuron $\rightarrow$ interneuron connections were restricted to motoneurons that activate buccal musculature. Motoneurons that innervate glandular structures or the gut, such as B1, B2, and B3 cells, were never found to have reciprocal connections with interneurons.

The role of the motoneurons in pattern generation was assessed by manipulating their firing activity during SO-driven feeding rhythms. In all cases, changes in motoneuron activity could reset the ongoing rhythm, and this occurred in a manner that was predictable on the basis of the electrotonic connections. Because these motoneurons (1) oscillate in a phase-locked manner with patterned output, (2) provide functionally relevant inputs to CPG interneurons, and (3) can disrupt CPG-driven patterned activity when manipulated within their normal physiological operating range, we now suggest that they should be regarded as members of the pattern-generating circuit for feeding.

The fact that the electrotonic connections are restricted to buccal muscle motoneurons suggests that another major function is to synchronize CPG and muscle activity by phase-locking the activities of pattern-generating interneurons and motoneurons. The motoneuron $\rightarrow$ interneuron electrotonic connections presumably ensure that activity in the feeding CPG is tightly coupled to the final behavioral expression of feeding. Electrotonic coupling is a recognized mechanism for synchronizing neuronal firing activity in both invertebrate (Wilson, 1966; Spira et al., 1980; Getting, 1989; Marder and Calabrese, 1996) and vertebrate motor pattern generation (Walton and Navarrete, 1991; Perrins and Roberts, 1995a). However, the buccal mass motoneurons have the ability to affect the CPG through these electrotonic connections because they also receive inputs from interneurons that are not coupled electrotonically either to the motoneurons or to the interneurons that normally drive them. Thus B7a is excited by the $\mathrm{N} 1 \mathrm{M}$ interneuron in the protraction phase, but it is inhibited by $\mathrm{N} 2$-type and N3-type interneurons that are active in the retraction and swallow phases, respectively (Rose and Benjamin, 1981a,b; Elliott and Kemenes, 1992; Brierley et al., 1997a). The N1M is coupled both chemically (Elliott and Kemenes, 1992) and electrotonically to B7a. However, the N2-type and N3-type interneurons are coupled only chemically to both B7 and N1M (Rose and Benjamin, 1981a,b; Elliott and Benjamin, 1985a; Brierley et al., 1997a,b). B10 is excited in both the N1 and N2 phase (Rose and Benjamin, 1981a; Elliott and Kemenes, 1992), but it is coupled electrotonically to N2-type cells only. B4/B4CL motoneurons are inhibited by both N1M and N2-type interneurons (Elliott and Kemenes, 1992; Brierley et al., 1997a). They also receive an inhibitory input from N3-type interneurons (Rose and Benjamin, 1981b), together with electrotonic excitation from the same cells.

The $\mathrm{B} 7 \mathrm{a} \rightarrow \mathrm{N} 1 \mathrm{M}$ electrotonic synapse was perhaps the most important connection investigated here. The strength of the coupling (up to $17 \%$ ) was sufficiently high to allow physiological levels of depolarization in B7a to evoke action potentials in N1M. Maintained depolarization of B7a could even drive a CPG feeding rhythm via the activation of N1M, although not so effectively as a modulatory interneuron like the SO. This indicates that activity in B7a contributes to the buildup of the protraction phase of the feeding rhythm in which the N1M cells are known to play a prominent role (Rose and Benjamin, 1981b; Elliott and Benjamin, 1985a). Therefore, B7a-type cells should be regarded as important protraction phase CPG neurons as well as motoneurons for buccal muscles.

The $\mathrm{B} 10 \rightarrow \mathrm{N} 2$ also contributes to rhythm generation, although its effects are not so strong as $\mathrm{B} 7 \mathrm{a} \rightarrow \mathrm{N} 1 \mathrm{M}$. However, it is likely to contribute to more than just one phase of the rhythm because, although it is most active during N2/rasp, it also is depolarized (via the $\mathrm{N} 1 \mathrm{M} \rightarrow \mathrm{B} 10$ chemical synaptic connection; Elliott and Kemenes, 1992) during the N1M/protraction phase. Although this depolarization during N1M is weaker than during N2, it still would help to depolarize the N2s during protraction. Both types of $\mathrm{N} 2(\mathrm{~N} 2 \mathrm{~d}$ and $\mathrm{N} 2 \mathrm{v}$ ) are depolarized slowly by other CPG interneurons during this phase of the cycle (Elliott and Benjamin, 1985b; Brierley et al., 1997b), and B10 $\rightarrow$ N2d/N2v coupling must provide a component of this. Eventually, the depolarization of the $\mathrm{N} 2 \mathrm{~s}$ triggers a plateau in $\mathrm{N} 2 \mathrm{v}$, triggering spike activity in both $\mathrm{N} 2$-type cells. Thus the B10 can be thought of as having a role in promoting the transition between the N1/protraction and N2/rasp phases of feeding.

$\mathrm{The} \mathrm{B} 4 \mathrm{CL} \rightarrow \mathrm{N} 3 \mathrm{p}$ connection may have a role to play in another transition, the change from the rasp to the swallow phase. Recent evidence (Yeoman et al., 1995) has shown that both of these cell types start to fire at the boundary of the N2 and N3 phases, making them suitable to promote the transition from rasp to swallow.

The B4 $\rightarrow$ N3t connection provides an important feedback mechanism that may have a limiting effect on the speed of the 
rhythm. When these motoneurons are depolarized to fire within their physiological range, this has a delaying effect on the onset of subsequent feeding cycles. We suggest that this effect may play a physiological role in the maintenance of cycle frequencies sustainable by the buccal muscles. This notion also is supported by results from preliminary laser photoinactivation experiments. Removal of both B4 cells from the feeding circuitry by photoablation leads to a significant increase in the frequency of the SO-driven fictive feeding rhythm (G. Kemenes, personal communication).

In other invertebrate systems, too, motoneuron $\rightarrow$ CPG connections have been reported. In the leech at least two motoneuron types have been shown to have connections with patterngenerating interneurons that control swimming (Friesen, 1989). Like the coupled motoneurons in Lymnaea, current injection into leech swimming motoneurons resets the phase of an ongoing pattern (Friesen, 1989). It also has been shown that elevation of serotonin levels allows the swim motoneurons to participate more strongly in the production of the motor pattern (Mangan et al., 1994). In Lymnaea, serotonin is an important neuromodulator in the feeding system (Yeoman et al., 1996), and it has been demonstrated that depletion of serotonin levels by neurotoxins or photoablation of identified serotonergic neurons leads to reduced rates of feeding in intact animals (Kemenes et al., 1991) and fictive feeding in isolated CNS preparations (Yeoman et al., 1994), respectively. It is interesting to speculate that the depletion of serotonin levels in these earlier experiments may have weakened the integration between motoneurons and interneurons, and this may have contributed to the reduction in feeding rates.

In the crustacean stomatogastric system, motoneurons and several interneurons are connected through electrotonic and chemical synapses, and the motoneurons take an active part in the rhythm generation (Selverston, 1989; Marder and Calabrese, 1996). Motoneuronal contributions to pattern generation also have been reported in the crab ventilatory system (Simmers and Bush, 1983) and the crayfish swimmeret system (Heitler, 1978), in which motoneurons are thought to provide a positive feedback loop to sustain and reinforce an ongoing pattern. In the sea slugs Tritonia and Aplysia, buccal and cerebral motoneurons can themselves drive repeating rhythms (Willows, 1980; Hurwitz et al., 1994; Perrins and Weiss, 1996), but these probably occur with the mediation of so-far unidentified CPG-type interneurons.

In the Xenopus embryo, an important lower vertebrate model, recent evidence suggests that motoneurons may have feedback pathways onto the interneurons that generate locomotion (Perrins and Roberts, 1995a,b). Among higher vertebrates there is at least one specific example of motoneurons synapsing with interneuronal targets. These are the spinal Renshaw cells involved in locomotion (for review, see Windhorst, 1990). Thus motoneuronal involvement in centrally generated patterns appears to be an important feature of simple and complex neuronal circuits underlying a wide variety of behaviors. The significance of finding a pattern-generating role for motoneurons in the Lymnaea feeding system is that this, unlike the numerically more complex vertebrate systems, is a network in which the cellular mechanisms of this role can be studied at the level of identified synaptic connections between all of the motoneurons and interneurons involved in the generation of a well defined behavioral pattern.

\section{REFERENCES}

Benjamin PR (1983) Gastropod feeding: behavioural and neural analysis of a complex multicomponent system. In: Neural origin of rhythmic movements (Roberts A, Roberts B, eds), pp 159-193. Cambridge, UK: Cambridge UP.

Benjamin PR, Elliott CJH (1989) Snail feeding oscillator: the central pattern generator and its control by modulatory interneurons. In: Neuronal and cellular oscillators (Jacklet J, ed), pp 173-214. New York: Dekker.

Benjamin PR, Rose RM (1979) Central generation of bursting in the feeding system of the snail, Lymnaea stagnalis. J Exp Biol 80:93-118.

Benjamin PR, Winlow W (1981) The distribution of three wide-acting inputs to identified neurones in the isolated brain of Lymnaea stagnalis. Comp Biochem Physiol [A] 70:293-307.

Benjamin PR, Rose RM, Slade CT, Lacy MG (1979) Morphology of identified neurones in the buccal ganglia of Lymnaea stagnalis. J Exp Biol 80:119-135.

Brierley MJ, Staras K, Benjamin PR (1997a) Behavioural function of glutamatergic interneurons in the feeding system of Lymnaea: plateauing properties and synaptic connections with motor neurons. J Neurophysiol 78:3386-3395.

Brierley MJ, Yeoman MS, Benjamin PR (1997b) Glutamatergic N2v cells are central pattern generator interneurons of the Lymnaea feeding system: new model for rhythm generation. J Neurophysiol 78:3396-3407.

Elliott CJH, Benjamin PR (1985a) Interactions of pattern-generating interneurons controlling feeding in Lymnaea stagnalis. J Neurophysiol 54:1396-1411.

Elliott CJH, Benjamin PR (1985b) Interactions of the slow oscillator interneuron with feeding pattern-generating interneurons in Lymnaea stagnalis. J Neurophysiol 54:1412-1421.

Elliott CJH, Benjamin PR (1989) Esophageal mechanoreceptors in the feeding system of the pond snail Lymnaea stagnalis. J Neurophysiol 61:727-736.

Elliott CJH, Kemenes G (1992) Cholinergic interneurons in the feeding system of the pond snail Lymnaea stagnalis. II. N1 interneurons make cholinergic synapses with feeding motoneurons. Philos Trans R Soc Lond [Biol] 336:167-180.

Elphick MR, Kemenes G, Staras K, O'Shea M (1995) Behavioral role for nitric oxide in chemosensory activation of feeding in a mollusc. J Neurosci 15:7653-7664.

Friesen WO (1989) Neuronal control of leech swimming movements. II. Motor neuron feedback to oscillator cells 115 and 28. J Comp Physiol [A] 166:205-215.

Getting PA (1989) Emerging principles governing the operation of neural networks. Annu Rev Neurosci 12:185-204.

Heitler WJ (1978) Coupled motoneurones are part of the crayfish swimmeret central oscillator. Nature 275:231-234.

Hurwitz I, Goldstein RS, Susswein AJ (1994) Compartmentalization of pattern-initiation and motor functions in the B31 and B32 neurons of the buccal ganglia of Aplysia californica. J Neurophysiol 71:1514-1527.

Kemenes G, Elliott CJH (1994) Analysis of the feeding motor pattern in the pond snail Lymnaea stagnalis: photoinactivation of axonally stained pattern generating interneurons. J Neurosci 14:153-166.

Kemenes G, Daykin K, Elliott CJH (1991) Photoinactivation of neurons axonally filled with the fluorescent dye 5(6)-carboxyfluorescein in the pond snail Lymnaea stagnalis. J Neurosci Methods 39:207-216.

Kemenes G, Staras K, Benjamin PR (1997) In vitro appetitive classical conditioning of the feeding response in the pond snail Lymnaea stagnalis. J Neurophysiol 78:2351-2362.

Kojima S, Nanakamura H, Nagayama S, Fujito Y, Ito E (1997) Enhancement of an inhibitory input to the feeding central pattern generator in Lymnaea stagnalis during conditioned taste-aversion learning. Neurosci Lett 230:179-182.

Mangan PS, Curran GA, Hurney CA, Friesen WO (1994) Modulation of swimming behavior in the medicinal leech. III. Control of cellular properties in motor neurons by serotonin. J Comp Physiol [A] 175:709-722.

Marder E, Calabrese RL (1996) Principles of rhythmic motor pattern generation. Physiol Rev 76:687-717.

Morton DW, Chiel HJ (1994) Neural architectures for adaptive behavior. Trends Neurosci 17:413-420.

Perrins R, Roberts A (1995a) Cholinergic and electrical motoneuronmotoneuron synapses contribute to on-cycle excitation during swimming in Xenopus embryos. J Neurophysiol 73:1005-1012.

Perrins R, Roberts A (1995b) Cholinergic contribution to excitation in a spinal locomotor central pattern generator in Xenopus embryos. J Neurophysiol 73:1013-1019. 
Perrins R, Weiss KR (1996) A cerebral central pattern generator in Aplysia and its connections with buccal feeding circuitry. J Neurosci 16:7030-7045.

Peters M, Altrup U (1984) Motor organization in pharynx of Helix pomatia. J Neurophysiol 52:389-409.

Rose RM, Benjamin PR (1979) The relationship of the central motor pattern of the feeding cycle of Lymnaea stagnalis. J Exp Biol 80:137-163.

Rose RM, Benjamin PR (1981a) Interneuronal control of feeding in Lymnaea stagnalis. I. Initiation of feeding by a single buccal interneuron. J Exp Biol 92:187-201.

Rose RM, Benjamin PR (1981b) Interneuronal control of feeding in Lymnaea stagnalis. II. The interneuronal mechanisms generating feeding cycles. J Exp Biol 92:203-228.

Selverston AI (1989) Lobster gastric mill oscillator. In: Neuronal and cellular oscillators (Jacklet J, ed), pp 339-370. New York: Dekker.

Selverston AI, Moulins M (1985) Oscillatory neural networks. Annu Rev Physiol 47:29-48.

Simmers AJ, Bush BMH (1983) Central nervous mechanisms controlling rhythmic burst generation in the ventilatory motoneurones of Carcinus maenas. J Comp Physiol [A] 150:1-21.

Spira ME, Spray DC, Bennett MVL (1980) Synaptic organization of expansion motoneurons of Navanax inermis. Brain Res 195:241-269.

Staras K, Kemenes G, Benjamin PR (1998) Neurophysiological correlates of unconditioned and conditioned feeding behavior in the pond snail Lymnaea stagnalis. J Neurophysiol, in press.

Walton KD, Navarrete R (1991) Postnatal changes in motoneurone elec- trotonic coupling studied in the in vitro rat lumbar spinal cord. J Physiol (Lond) 433:283-305.

Whelan HA, McCrohan CR (1996) Food-related conditioning and neuronal correlates in the freshwater snail Lymnaea stagnalis. J Moll Stud 62:483-494.

Willows AOD (1980) Physiological basis of feeding behaviour in Tritonia diomedia. II. Neuronal mechanisms. J Neurophysiol 44:849-861.

Wilson DM (1966) Central nervous mechanisms for the generation of rhythmic behaviour in arthropods. Symp Soc Exp Biol 20:199-228.

Windhorst U (1990) Activation of Renshaw cells. Prog Neurobiol 35:135-179.

Yeoman MS, Parish DC, Benjamin PR (1993) A cholinergic modulatory interneuron in the feeding system of the snail, Lymnaea. J Neurophysiol 70:1-13.

Yeoman MS, Kemenes G, Benjamin PR, Elliott CJH (1994) Modulatory role for the serotonergic cerebral giant cells in the feeding system of the snail, Lymnaea. II. Photoinactivation. J Neurophysiol 72:1372-1382.

Yeoman MS, Vehovszky Á, Kemenes G, Elliott CJH, Benjamin PR (1995) Novel interneuron having hybrid modulatory central pattern generator properties in the feeding system of the snail, Lymnaea stagnalis. J Neurophysiol 73:112-124.

Yeoman MS, Brierley MJ, Benjamin PR (1996) Central pattern generating interneurons are targets for the modulatory serotonergic cerebral giant cells in the feeding system of Lymnaea. J Neurophysiol 75:11-25. 